November 2003 - NREL/SR-560-34588

\title{
DER Certification Laboratory Pilot, Accreditation Plan, and Interconnection Agreement Handbook
}

T. Key, H.E. Sitzlar, and R. Ferraro

EPRI PEAC Corp.

Knoxville, Tennessee

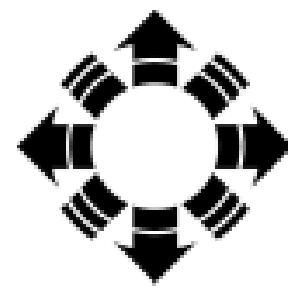

\section{NPEI}

National Renewable Energy Laboratory

1617 Cole Boulevard

Golden, Colorado 80401-3393

NREL is a U.S. Department of Energy Laboratory Operated by Midwest Research Institute • Battelle

Contract No. DE-AC36-99-G010337 


\section{DER Certification Laboratory Pilot, Accreditation Plan, and Interconnection Agreement Handbook}

T. Key, H.E. Sitzlar, and R. Ferraro EPRI PEAC Corp. Knoxville, Tennessee

NREL Technical Monitor: T. Basso

Prepared under Subcontract No. NAD-1-30605-13

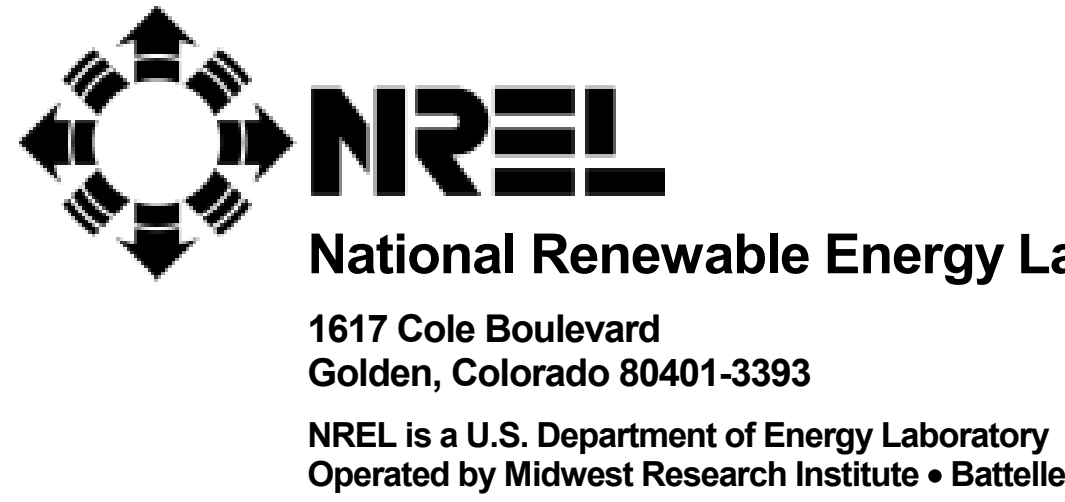

Contract No. DE-AC36-99-G010337 


\section{NOTICE}

This report was prepared as an account of work sponsored by an agency of the United States government. Neither the United States government nor any agency thereof, nor any of their employees, makes any warranty, express or implied, or assumes any legal liability or responsibility for the accuracy, completeness, or usefulness of any information, apparatus, product, or process disclosed, or represents that its use would not infringe privately owned rights. Reference herein to any specific commercial product, process, or service by trade name, trademark, manufacturer, or otherwise does not necessarily constitute or imply its endorsement, recommendation, or favoring by the United States government or any agency thereof. The views and opinions of authors expressed herein do not necessarily state or reflect those of the United States government or any agency thereof.

Available electronically at http://www.osti.gov/bridge

Available for a processing fee to U.S. Department of Energy and its contractors, in paper, from:

U.S. Department of Energy

Office of Scientific and Technical Information

P.O. Box 62

Oak Ridge, TN 37831-0062

phone: 865.576 .8401

fax: 865.576.5728

email: reports@adonis.osti.gov

Available for sale to the public, in paper, from:

U.S. Department of Commerce

National Technical Information Service

5285 Port Royal Road

Springfield, VA 22161

phone: 800.553.6847

fax: 703.605.6900

email: orders@ntis.fedworld.gov

online ordering: http://www.ntis.gov/ordering.htm 


\section{Preface}

This annual report covers work performed by EPRI PEAC Corp. during the base period of a multiyear effort under Department of Energy/National Renewable Energy Laboratory contract NAD-1-30605-13 "DER Certification Laboratory Pilot, Accreditation Plan, and Interconnection Agreement Handbook."

The following personnel at EPRI PEAC Corp. have contributed to the technical efforts covered in this report:

- Thomas S. Key (primary contributor)

- Harvey E. Sitzlar

- Ralph J. Ferraro. 


\section{Acronyms}

$\begin{array}{ll}\text { AHJ } & \text { authority (or authorities) having jurisdiction } \\ \text { ANSI } & \text { American National Standards Institute } \\ \text { CSA } & \text { Canadian Standards Association } \\ \text { DER } & \text { distributed energy resource(s) } \\ \text { DG } & \text { distributed generation } \\ \text { DOE } & \text { Department of Energy } \\ \text { DR } & \text { distributed resource(s) } \\ \text { EGSA } & \text { Engine Generator Systems Association } \\ \text { EPA } & \text { Environmental Protection Agency } \\ \text { EPS } & \text { electric power system } \\ \text { ESP } & \text { energy service provider } \\ \text { FERC } & \text { Federal Energy Regulatory Commission } \\ \text { IEC } & \text { International Electrotechnical Commission } \\ \text { IEEE } & \text { Institute of Electrical and Electronics Engineers } \\ \text { NEC } & \text { National Electric Code } \\ \text { NEMA } & \text { National Electrical Manufacturing Association } \\ \text { NERC } & \text { North American Electric Reliability Council } \\ \text { NESC } & \text { National Electrical Safety Code } \\ \text { NFPA } & \text { National Fire Protection Agency } \\ \text { NREL } & \text { National Renewable Energy Laboratory } \\ \text { OEM } & \text { original equipment manufacturer } \\ \text { PCC } & \text { point of common coupling } \\ \text { PUC } & \text { public utility commission } \\ \text { PV } & \text { photovoltaic(s) } \\ \text { SC } & \text { system compatibility } \\ \text { SCC } & \text { Standards Coordinating Committee } \\ \text { UL } & \text { Underwriters Laboratories }\end{array}$




\section{Abstract}

This report describes the first steps toward creating the needed organization, procedures, plans and tools for distributed energy resources (DER) equipment certification, test laboratory accreditation, and interconnection agreements. The approach is a collaborative initiative among government, manufacturers, and electric power utilities - all of which are key stakeholders in the future acceptance and use of DER. The work reported includes a draft plan for certification, a beta Web site to support communications and materials, and preliminary draft certification criteria. These may be used by DER stakeholders to simplify interconnection agreements between system operators, independent power producers, and distribution companies. Ultimately, the goal of truly simplified interconnection can be accomplished by creating organizational procedures and easy-to-follow methods to support a national DER certification and laboratory accreditation program.

This report covers the activities and accomplishments during the first period of a multiyear effort. It summarizes steps taken to outline a certification plan to assist in the future development of an interim plan for certification and accreditation activities. Report sections review fundamental elements of certification and accreditation criteria to build future expanded and more comprehensive programs to help DER equipment manufacturers be able to offer certified DER products.

The multiyear subcontract has two thrusts for DER interconnection, certification, and laboratory accreditation:

1. Certification and laboratory accreditation model program One of the results of this subcontract will be an industrywide certification and laboratory accreditation model program that can evolve and be implemented.

2. Interconnection agreements information

In addition, this work will include a review, analysis, and proposed resolution of technical and nontechnical requirements being developed by states for interconnection; a distributed electric power interconnection agreement handbook; and other services supporting interconnection agreements. 


\section{Table of Contents}

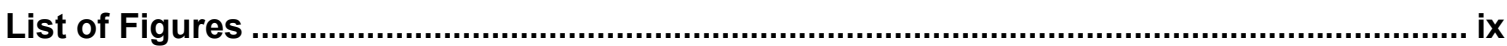

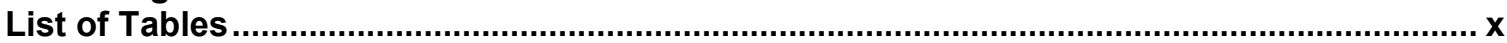

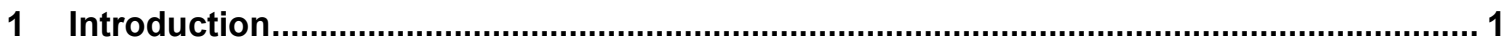

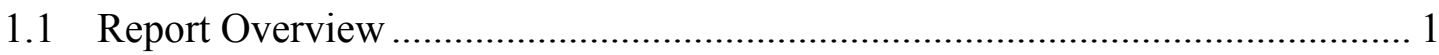

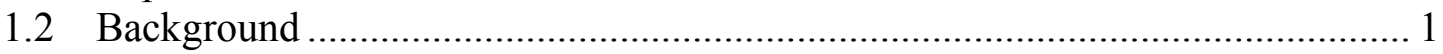

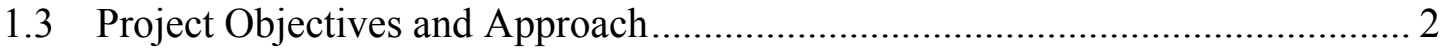

1.4 Project Tasks and Activities: Expected Results ............................................. 3

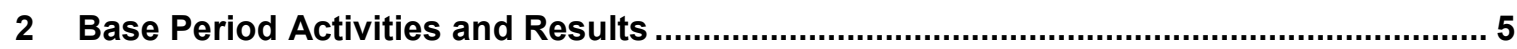

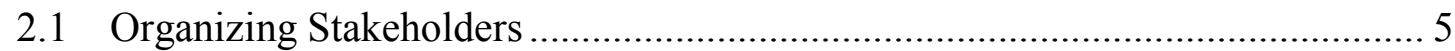

2.2 Certification and Accreditation Plan for the Interconnection of DER ................ 6

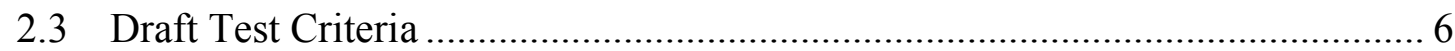

2.4 Overview of DER Interconnection Agreements .......................................... 6

2.5 Interconnection Agreement Handbook Outline and Plan ................................... 7

2.6 DER Interconnection Web Site .................................................................. 7

3 Model Certification Program and Interconnection Standards ........................................ 8

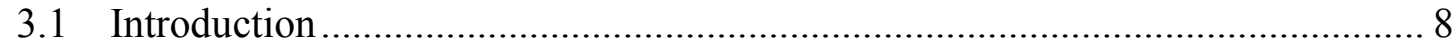

3.2 Model Photovoltaic Module Certification Program........................................... 8

3.3 Proposed Distributed Energy Resources Series of Certification Documents ...... 9

3.4 Coordination With Other Agencies................................................................. 10

3.5 Role of IEEE Standards in the Interconnection of Distributed Energy

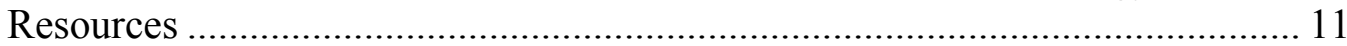

3.6 IEEE 1547 DER Interconnection Standard................................................... 12

3.7 IEEE 1547 Series of Distributed Energy Resources Interconnection

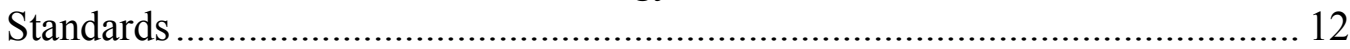

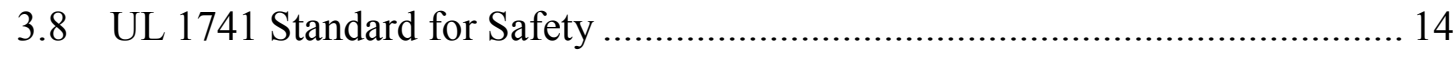

4 Overview of the Certification and Accreditation Web Site .............................................. 15

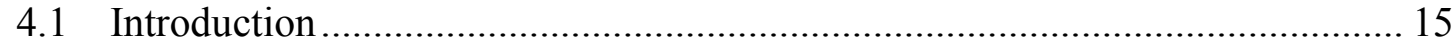

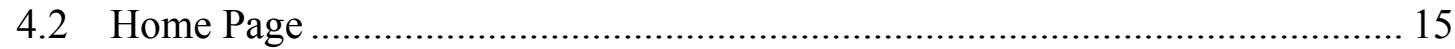

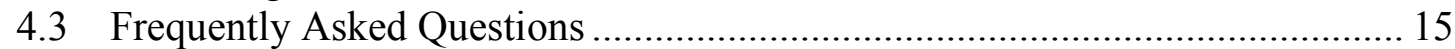

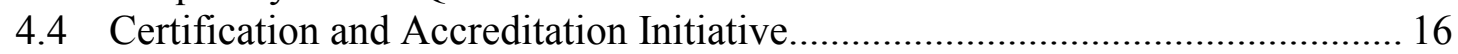

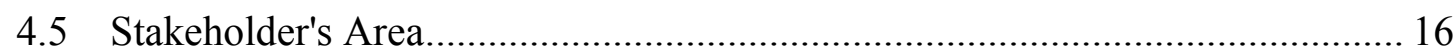

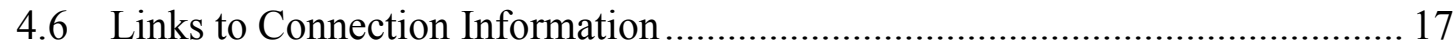

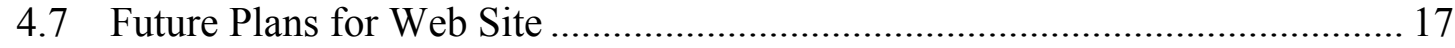

5 Looking Ahead: Where We Go From Here ................................................................. 18 


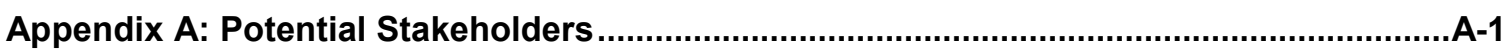

Appendix B: Test and Evaluation Criteria for Certification of DER Interconnection

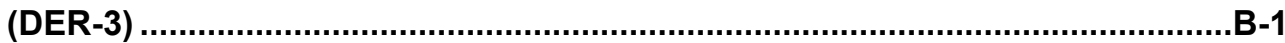

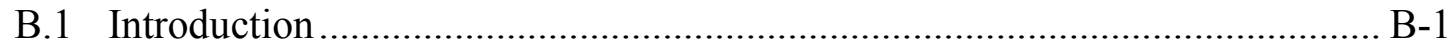

B.2 Purpose and Scope .......................................................................... B-1

B.3 Acronyms Used ............................................................................... B-2

B.4 Procedural Definitions ............................................................................... B-2

B.5 Technical Definitions ........................................................................ B-4

B.6 Test and Evaluation Criteria............................................................... B-10

B.7 Evaluation Process …........................................................................ B-11

B.8 Reporting ........................................................................................ B-13

B.9 General Organization ................................................................... B-21

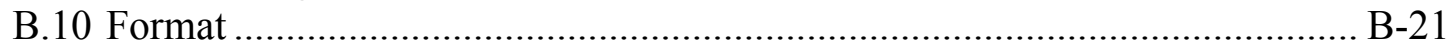

B.11 Peer Review for Consensus on Test Protocol .............................................. B-22

B.12 Applying Protocols for Future Certification of Distributed Resources ......... B-22

B.13 Pilot Testing to Support Protocol Development .......................................... B-22

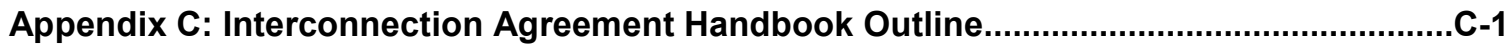

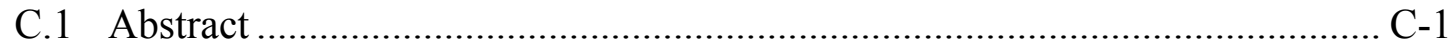

C.2 Acknowledgments....................................................................................

C.3 Criteria Implementation Committee Members ……..................................... C-1

C.4 Introduction to Interconnection Agreement Handbook ................................ C-1

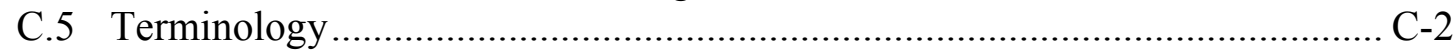

C.6 Interconnection Agreement Contents..................................................... -2

C.7 Interconnection Application Process......................................................... C-3

C.8 Authority Having Jurisdiction Review Process ........................................... C-4

C.9 Interconnection Guidelines ...................................................................... C-5

C.10 Interconnection Agreement Template......................................................... C-7

C.11 Sample Interconnection Application Forms …......................................... C-7

C.12 Sample Interconnection Agreements .......................................................... C-7

C.13 References ................................................................................. C-7

Appendix D: EPRI PEAC Corp. Scope of Work

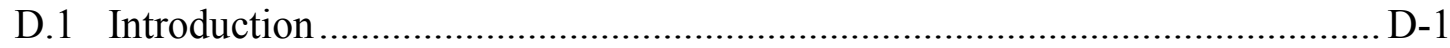

D.2 Base Period: Tasks 1-2 .................................................................... D-2

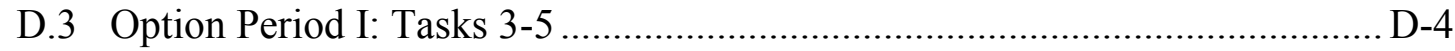

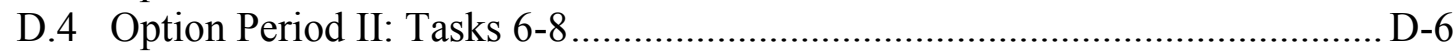

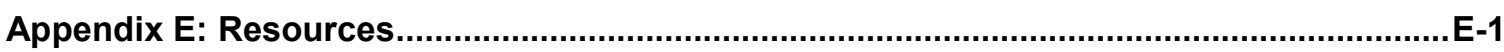

E.1 History of Interconnection Standards.............................................................

E.2 Federal DER Interconnection Rules and Agreements ......................................

E.3 State Interconnection Rules and Agreements ...................................................

E.4 Utility Rules and Interconnection Agreements ..............................................

E.5 Interconnection Rules and Agreements of Other Organizations........................6-6

E.6 DER Interconnection Tools ...........................................................................

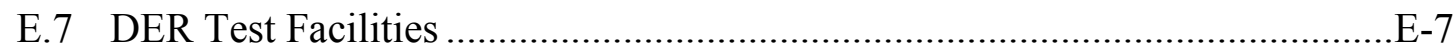

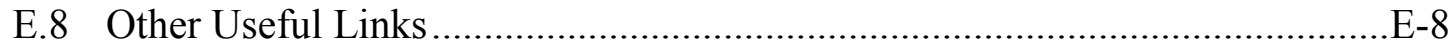




\section{List of Figures}

Figure 1. Examples of distributed energy resources............................................... 2

Figure 2. Steps required to establish a certification and labeling program ................. 3

Figure 3. Overview of IEEE SCC21 DER interconnection standards ....................... 13

Figure 4. Home page of DER certification Web site............................................ 15

Figure 5. Stakeholder's Working Area of DER certification web site ....................... 16

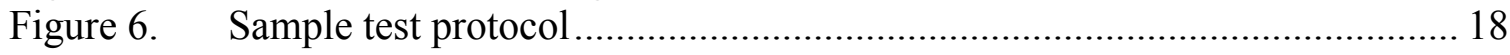

Figure A-1. Letter of invitation sent to stakeholders .............................................. A-2

Figure B-1. Area EPS..................................................................................... B-5

Figure B-2. Laboratory organization............................................................ B-16 


\section{List of Tables}

Table 1. Agencies That Make Codes, Standards, and State and Federal Rules

Related to the Compatibility Certification of DER With Power Systems ...... 11

Table B-1. A Family of Application-Specific Test Protocols for End-Use

Equipment and Distributed Resources .................................................. B-20 


\section{Introduction}

\subsection{Report Overview}

This annual report describes EPRI PEAC Corp.'s activities and accomplishments for the base period of National Renewable Energy Laboratory (NREL) subcontract NAD-1-30605-13 under prime contract DE-AC36-99GO10337. It reviews the steps taken by EPRI PEAC during the base period to create the organization, procedures, and plans for distributed energy resources (DER) interconnection equipment certification and test laboratory accreditation as well as to provide tools to support simplified interconnection agreements. The base period of the contract involved identifying and organizing stakeholders, developing draft discussion plans and other activities to establish a draft model program for certification and labeling of DER, developing preliminary draft certification test criteria, reviewing and analyzing interconnection requirements developed by states and other organizations, developing a beta Web site to support communication among stakeholders, and drafting an outline for a distributed electric power interconnection agreement handbook.

Section 1 of the report describes the report content. It includes background information and an overview of the project objectives, approach, and roles. Section 2 summarizes EPRI PEAC's activities and results during the base period. Section 3 presents a series of photovoltaics (PV) certification documents that can be used as a model for developing DER interconnection certification documents. It also briefly describes the requirements for coordination with other agencies and provides an update on relevant Institute of Electrical and Electronics Engineers (IEEE) interconnection standards. The stakeholders' beta Web site is described in Section 4, and Section 5 describes future tasks for EPRI PEAC in the certification effort. The report provides the fundamental draft elements of certification test criteria as the first step toward more comprehensive programs in the future.

Appendix A lists the organizations that have been identified as potential stakeholders and the individuals who have demonstrated interest in participating in the certification effort. Appendix B is the initial discussion draft of "Test and Evaluation Criteria for Certification of DER Interconnection." Appendix $\mathrm{C}$ is the initial discussion draft outline and plan of DER Interconnection Agreement Handbook, and Appendix D lists all the project tasks that have been laid out for EPRI PEAC in the certification and accreditation endeavor. Appendix E contains applicable resources and references.

\subsection{Background}

Interest in distributed generation (DG) has increased substantially over the past few years because of its potential to provide increased reliability and lower-cost power. DER may be one of the more promising keys to stabilizing energy price spikes, providing power during critical outages, mitigating electric power quality disturbances, and improving air quality while providing a reasonable return on investment. Distributed power technologies (see examples in Figure 1) will play a key role in the reliability, power quality, security, and environmental friendliness of the electric power system (EPS) of the future. 
The goal and vision for the 21st century of the Department of Energy's (DOE's) Distribution and Interconnection R\&D is to capture the full value of DER, including both generation and storage technologies. This will require an electricity market that enables DG users to buy and sell power, employ load management, and provide support services in a manner similar to that of electric service providers. The technologies and operational concepts to properly and efficiently integrate DER into the electric service system must be developed to realize these benefits and avoid negative effects on electric system reliability and safety.

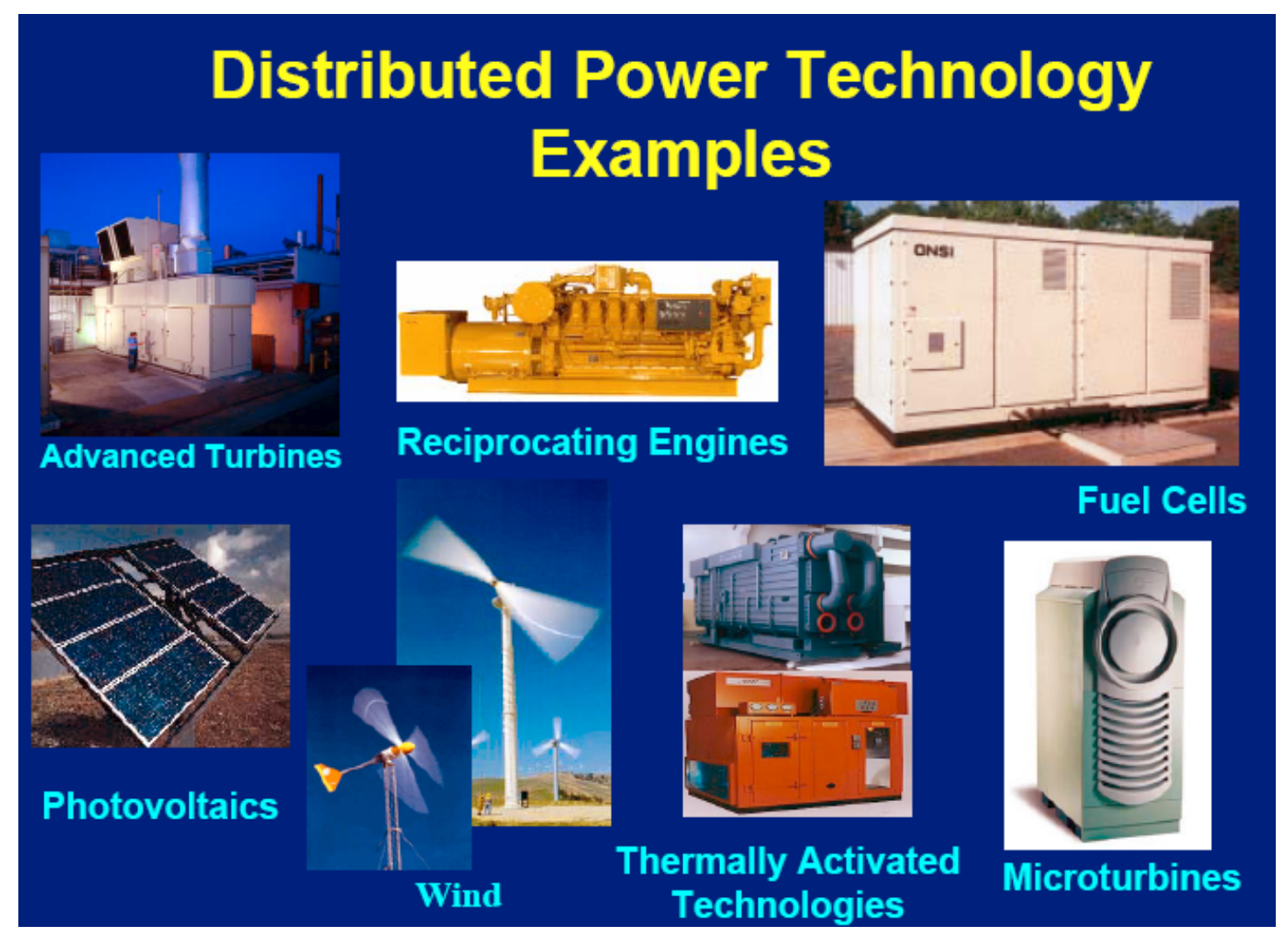

Figure 1. Examples of distributed energy resources (NREL)

\subsection{Project Objectives and Approach}

EPRI PEAC's objectives in this project are to create the needed organization, procedures, plans, and tools for distributed resource (DR) equipment certification and test laboratory accreditation and to establish tools that support simplified interconnection agreements. This involves a collaborative initiative among government, DER equipment manufacturers, and electric power utilities, all of which are key stakeholders in the future acceptance and use of DER. As depicted in Figure 2, the path to DER certification and labeling will require a coordinated effort among stakeholders working toward the common goal of certified "grid compatible" DER systems and interconnection equipment that can be efficiently and safely interconnected. 


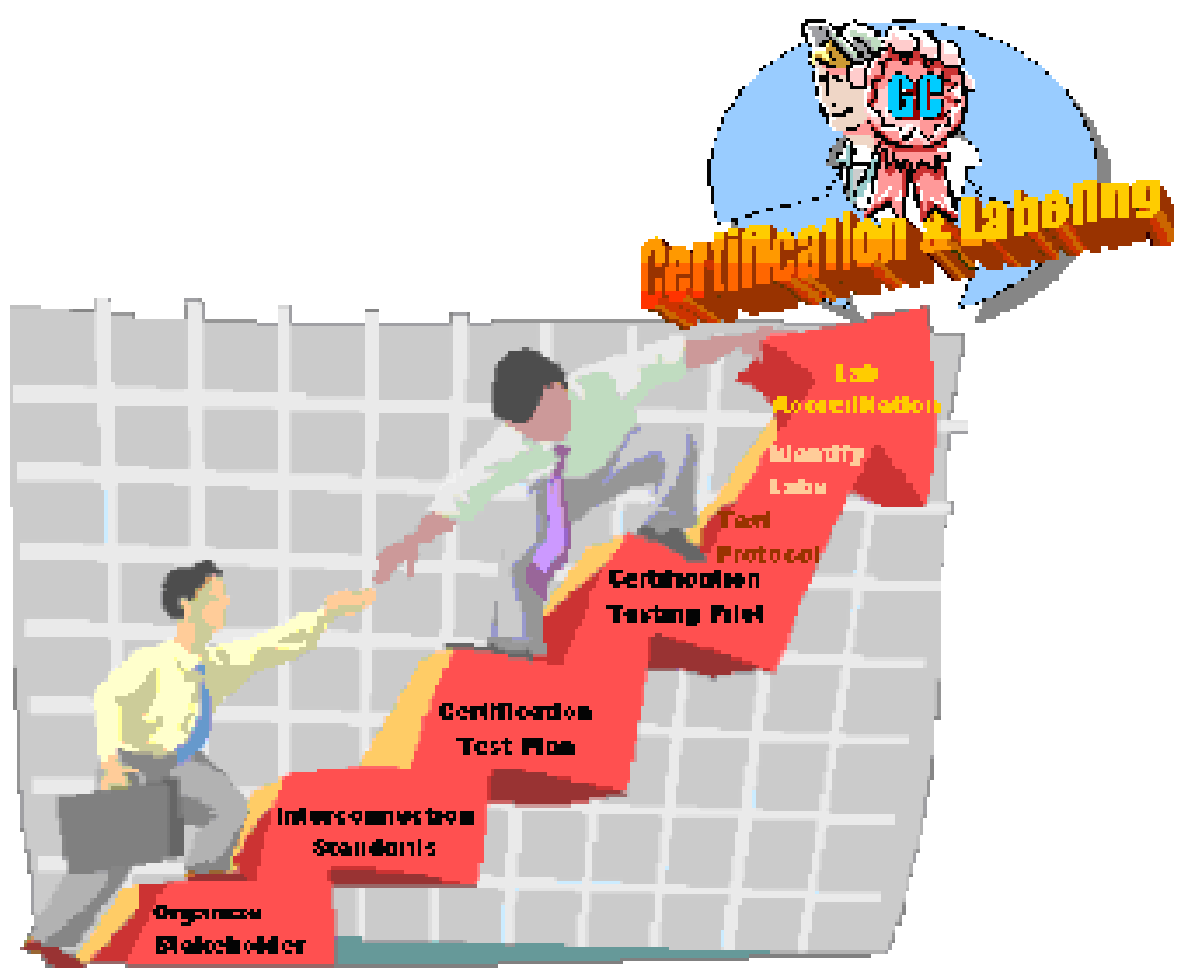

Figure 2. Steps required to establish a certification and labeling program

The approach is to develop a certification and laboratory accreditation pilot effort applicable to a broad spectrum of DER equipment and user communities. This approach helps promote industrywide acceptance by creating an advisory board, soliciting inputs on testing and reporting procedures, and providing standard test protocols that describe rationale and expected results. The pilot testing and certification process will be demonstrated, and an implementation plan for DER certification and laboratory accreditation will be drafted. Test and certification criteria, an interconnection agreement handbook, and a Web-based interconnection information resource will be developed. Also, tools - such as problem-solving forums, Web-based training, organizational workshops, and related communication mechanisms - will be established.

The interconnection agreement results will ameliorate universal technical and nontechnical issues common to differing interconnection agreements throughout the United States. The approach will promote consideration of local needs and requirements and the needs and requirements arising from broader universal considerations of interconnection.

\subsection{Project Tasks and Activities: Expected Results}

EPRI PEAC is under contract to organize stakeholders and develop tools for the future implementation of a certification program covering interconnection equipment and systems. Stakeholders are being engaged and organized to help develop an acceptable plan for certification that builds on the knowledge gained from ongoing systems integration activities. 
Part of the subcontract work at EPRI PEAC involves outlining a plan, including preliminary certification criteria, to simplify interconnection agreements between system operators, independent power producers, and distribution companies. The approach, which is expected to promote industrywide acceptance of DER, is for stakeholders to collaborate in the development of criteria for testing, evaluating, and "labeling" DER equipment. This way, there will be a common benchmark for equipment certification and laboratory accreditation, and there will be a common baseline for consideration in the development of interconnection agreements. These goals can be accomplished by creating organizational procedures and easyto-follow methods to support a DER certification and laboratory accreditation program.

The expected results of this subcontract are an industrywide certification and laboratory accreditation model program that can evolve and be implemented. EPRI PEAC will do this by first organizing stakeholders and then developing a plan for conducting certifications and accrediting a nationwide network of laboratories to provide testing and services. Next, EPRI PEAC will enlist several DER manufacturers and host utilities to participate in a pilot testing and certification process. Finally, EPRI PEAC will refine the process and documents for use at other laboratory facilities, for training, and for developing the handson skills of training service personnel, laboratory engineers, field engineers, and other professional service participants.

Specific tasks include establishing stakeholder roles and responsibilities, rules of engagement, and structure and procedures that lead to the creation of a pilot third-party testing activity. Through this approach, EPRI PEAC will create a governing board, solicit inputs on testing and reporting procedures from stakeholders, and design a standard test protocol template that describes rationale and expected results. Supporting tasks will provide tools such as problem-solving forums, Web-based training, organizational workshops, and communications mechanisms. Further, the subcontract work includes a review, analysis, and proposed resolution of technical and nontechnical requirements being developed by states for interconnection and the development of a distributed electric power interconnection agreement handbook to address technical and nontechnical "dos and don'ts" to be considered in the development of interconnection agreements; templates for interconnection agreements; and other services supporting interconnection agreements. Results from testing and any required simulation and analysis will provide sound inputs to the agreement process or the resolution of disputes. 


\section{Base Period Activities and Results}

\subsection{Organizing Stakeholders}

Organizing and coordinating stakeholder activities will be an ongoing activity. Contacting and recruiting stakeholders for the oversight board began in late 2001 at the EPRI Fall Distributed Resources Advisory Council meeting (Knoxville, Tennessee) and the IEEE Standards Coordinating Committee (SCC) 21 P $1547^{\mathrm{TM}}$ Working and Ballot Member Group meetings (Las Vegas, Nevada).

During the subcontract base period, more than 30 potential DER stakeholder advisors were identified. These included representatives of:

- IEEE SCC21 on Fuel Cells, Photovoltaics, Dispersed Generation, and Energy Storage, the working group for IEEE 1547 - 2003 Standard for Interconnecting Distributed Resources With Electric Power Systems

- UL 1741 Standard for Safety of Inverters, Converters, and Controllers for Use in Independent Power Systems Standards Technical Panel

- Manufacturers of interconnection hardware for DER systems and components

- The electric utility industry.

Other industry-recognized experts were also included.

Individuals have been solicited to help with the certification effort. See Appendix A for a list of their organizations. These individuals were invited to develop a draft plan for the certification and accreditation program and assist with development of the interim plan for certification and accreditation activities. By involving these key individuals and organizations in the conceptualization and refinement of the DER certification and accreditation plan, the tasks of the subcontract will be realized. More importantly, as stakeholders embrace DER certification and accreditation, many organizations will benefit.

- Utilities will be able to provide their customers with timely information about DER systems, which can significantly accelerate industry acceptance.

- DER equipment manufacturers will be strategically positioned to better understand key issues that relate to developing new markets for their products.

- Professional service companies will be able to reevaluate their present services and capabilities to determine their future role in the emerging DER market.

- Critical DER component suppliers will have ongoing communication channels with a spectrum of organizations, which will lead to a better understanding of industry needs.

- Academia will better identify and define courses and more focused R\&D projects.

- Associations and standards-making bodies will exchange information and avoid duplication of effort. 


\subsection{Certification and Accreditation Plan for the Interconnection of DER}

The draft certification and accreditation plan for the interconnection of DER is being developed via industry participation and consensus and through the creation of an informal oversight board. For a starting point, a discussion draft is under development. It will be reviewed by oversight board members. Feedback from stakeholders will be an ongoing activity, and constructive feedback will continue to help refine the document.

The initial draft plan will focus on three elements of the proposed certification and accreditation program:

1. Specific areas that need to be worked on to define the infrastructure

2. Support materials and services

3. Test plans for pilot testing.

\subsection{Draft Test Criteria}

Test protocols need to be developed as part of the certification program. Using existing test plans and standards combined with information from the certification pilot testing, stakeholder feedback, and years of equipment characterization and test protocol development, EPRI PEAC is developing criteria for a draft DER interconnection certification test protocol. See Appendix B for details.

Test protocol documents are necessarily "living documents" that will become more refined with each new testing experience. The process begins with a basic test plan that addresses the concerns without specific test specifications. Using the test plan for testing helps refine the procedure and often raises new issues and provides new observations that must be added to the procedure. After the testing, the test plan is enhanced with the addition of lessons learned. It becomes the basis for the draft test protocol document, which will ultimately become a formal test protocol document. This, in turn, will be used for all subsequent certification testing of specific DER equipment.

The draft test criteria include:

1. A description of the DER certification and accreditation documents

2. General test and evaluation criteria

3. Technical criteria for grid interconnection

4. An overview of future application-specific protocols for testing and labeling.

\subsection{Overview of DER Interconnection Agreements}

An Internet search was conducted to identify interconnection rules, guidelines, requirements, and agreements by federal and state regulatory authorities, individual utilities, and other organizations. A list of relevant links and a library of sample interconnection-related documents were compiled. Examples of interconnection agreements from selected states and organizations as well as links to many other resources are included in Appendix E. 


\subsection{Interconnection Agreement Handbook Outline and Plan}

An outline and plan for review of a DER interconnection handbook were developed to identify key elements proposed for inclusion. This initial draft for review outlines the handbook's purpose and objectives, various state interconnection requirements, terminology, interconnection agreement contents, the interconnection application process, the authorities having jurisdiction (AHJ) and electric service provider initial review process, interconnection guidelines, and an interconnection agreement template.

The purpose of the handbook is to provide procedures and guidance, pertinent information, and resources aimed at standardizing and simplifying the interconnection requirements for DER. It will include the requirements of specific states and present examples of interconnection agreements. Although the actual requirements may vary by location and jurisdiction, the handbook will attempt to address the important issues that owners of DER will be likely to confront during the interconnection process. See Appendix C for more detail.

\subsection{DER Interconnection Web Site}

To further encourage the coordinated deployment of DER systems, EPRI PEAC developed a special beta Web site (http://www.epri-peac.com/dr_certification_site/index.html) during the base period to facilitate communications for the education of the general public on matters pertaining to the certification of DER. This Web site is intended to be a repository of information and includes a plan and roadmap aimed at organizing the stakeholders and forming a national collaboration for the establishment of a draft model certification and laboratory accreditation program. The site contains Web-based information resources to assist with the development of the DER certification process. It contains information about certification requirements and is intended to support the interconnection handbook, typical interconnection agreements, and accreditation procedures to be developed in future tasks. The site will provide interconnection and certification information for specific DER interconnection technologies and will include links to major DER interconnection equipment manufacturers and distributors, DER standards activities, and state regulatory agencies. Section 4 provides a more detailed overview of the Web site. 


\section{Model Certification Program and Interconnection Standards}

\subsection{Introduction}

Section 3 introduces a successful certification program developed for PV modules. This program is suggested as a model for a similar series of certification documents for the DER interconnection certification program. Section 3 also introduces agencies that will likely have roles in the DER program and includes an update on relevant IEEE interconnection standards.

\subsection{Model Photovoltaic Module Certification Program}

Prior work by NREL and Arizona State University has resulted in a successful PV module certification program. This program is described in two NREL reports. One report covers criteria development, ${ }^{1}$ and the other is an implementation handbook. ${ }^{2}$ Both reports are available on DOE's Office of Scientific and Technology Information Web site (http://www.osti.gov/bridge/index.jsp).

This PV module certification program is being extended for PV systems. The organization and development for PV provides a good model for DER certification. In the PV program, documents define the program and provide procedural, business, and technical criteria. These documents are being updated for application to entire PV systems and include:

- PV-1 Criteria for a Model Quality System for Laboratories Engaged in Testing Photovoltaic Products

- PV-2 Model for a Third-Party Certification and Labeling Program for Photovoltaic Products

- $\quad$ PV-3 Test and Evaluation Requirements

o PV-3.1 Test and Evaluation Requirements for Certifying Photovoltaic Module Qualification

o PV-3.2 Test and Evaluation Requirements for Certifying Standalone Photovoltaic System Performance

o PV-3.3 Planned to be Design and Documentation Review and Evaluation Requirements for Grid-Tied Residential and Small Commercial PV Systems

o PV-3.4 Will cover Module Energy Ratings

o $\quad$ PV-3.5 Will cover Inverter Tests and Evaluations

\footnotetext{
${ }^{1}$ Osterwald, C.R.; Hammond, R.L.; Wood, B.D.; Backus, C.E.; Sears, R.L.; Zerlaut, G.A.; D’Aiello, R.V. Photovoltaic Module Certification/Laboratory Accreditation Criteria Development. NREL-TP-412-7680. Golden, CO: National Renewable Energy Laboratory. April 1995.

${ }^{2}$ Osterwald, C.R.; Hammond, R.L.; Wood, B.D.; Backus, C.E.; Sears, R.L.; Zerlaut, G.A.; D’Aiello, R.V. Photovoltaic Module Certification/Laboratory Accreditation Criteria Development: Implementation Handbook. NREL/TR-412-21291. Golden, CO: National Renewable Energy Laboratory. August 1996.
} 
- PV-4 Operational Procedures Manual

- PV-5 Application and Certification Procedures.

\subsection{Proposed Distributed Energy Resources Series of Certification Documents}

The current direction for certifying the interconnection of DR is to focus on the interconnection and not on the more general certification of equipment or system performance (i.e., not on components or general aspects such as emissions or efficiency). Following the current model for PV systems, five documents are envisioned for the certification of DER interconnection.

- DER-1 Criteria for a Model Quality System for Laboratories Engaged in Testing Distributed Energy Resource Interconnection Products

This document would address the DER quality system for accredited laboratories (criteria for a model similar to that used for PV-1).

- DER-2 Model for a Third-Party Certification and Labeling Program for Distributed Energy Resource Interconnection Products

This document would include the third-party certification and labeling plan and roadmap (model similar to that used for PV-2).

- DER-3 Test and Evaluation Requirements for Distributed Energy Resource Interconnection Products

DER-3 will include descriptions of the DR certification and accreditation documents, the overall procedure, the general test and evaluation criteria (modeled after PV-3), and the technical criteria specific for grid interconnection (modeled after PV-3.3). DER-3 will also describe possible future application-specific protocols for testing and labeling, focusing solely on certifying interconnections and eventually accrediting laboratories to provide the interconnection certifications. See Appendix B.

The test methods and procedures chosen for this purpose have been developed as national or international consensus standards (e.g., by the American Society for Testing Materials, IEEE, the American National Standards Institute [ANSI], Underwriters Laboratories [UL], the International Electrotechnical Commission [IEC], and the Engine Generator Systems Association), by other reputable technical organizations, or in relevant scientific texts or journals. DER-3 provides general requirements; specific testing and evaluation requirements may need to be provided in individual subdocuments. Each specific subdocument may be written to cover a unique DER interconnection system component or system type (e.g., utility, industrial, commercial, or residential) that may involve testing.

These proposed test methods and procedures represent the minimum testing requirements for a DER product certification and labeling program. In addition, these proposed test procedures and the concomitant equipment and facilities requirements represent the minimum test capabilities against which laboratories will be evaluated for testing in support of a DER interconnection certification and labeling program. 
If needed in the future, DER-3 can be arranged with subdocuments-DER-3.1, 3.2, 3.3, etc. - that cover unique aspects of the DER interconnection areas of concern (e.g., networks). These subdocuments will need to be created, revised, or enhanced when new or improved methods are developed or when a DER product certification and labeling program is expanded to cover new aspects of testing and certification.

- DER-4 Operational Procedures for Certification of Distributed Energy Resource Interconnection Equipment DER-4 will include the operational procedures for the certification body of a DER interconnection certification program (model similar to that used for PV-4).

- DER-5 Application and Certification Program

DER-5 will be a model similar to that used for PV-5.

The DER series of documents is intended to serve as a vehicle for constructive feedback from all DER stakeholders in the definition of proper DER equipment performance envelopes and issues related to interconnections with the electric service supply. Industrywide feedback on the draft criteria will be critical for addressing the level of knowledge required of those who work with DER equipment and interconnection activities. Although the criteria may need to differ in some respects to account for unique characteristics of select DER technologies or for equipment rating, the criteria will assist DER stakeholders with equipment choices and safety and reliability elements. To the extent possible, the criteria may also be helpful to selective agencies required to develop and implement plans to mitigate barriers to the long-term deployment of DER.

\subsection{Coordination With Other Agencies}

The requirements of the proposed DER series of documents will need to be coordinated with the existing interconnection regulations of various agencies.

Table 1 shows some of the state and federal agencies engaged in making codes, standards, and rules related to the interconnection of DER equipment. 
Table 1. Agencies That Make Codes, Standards, and State and Federal Rules Related to the Compatibility Certification of DER With Power Systems

\begin{tabular}{|c|c|c|c|c|c|}
\hline $\begin{array}{l}\text { Objectives for } \\
\text { DER Connection }\end{array}$ & Operate Safely & $\begin{array}{l}\text { Maintain } \\
\text { Reliability }\end{array}$ & $\begin{array}{l}\text { High-Quality } \\
\text { Performance }\end{array}$ & $\begin{array}{l}\text { No Harm to } \\
\text { Environment }\end{array}$ & $\begin{array}{c}\text { Cost- } \\
\text { Effective } \\
\text { Operation }\end{array}$ \\
\hline Area EPS & $\begin{array}{l}\text { ANSI (NESC), } \\
\text { IEEE }\end{array}$ & $\begin{array}{l}\text { NERC, } \\
\text { IEEE }\end{array}$ & $\begin{array}{l}\text { ANSI, IEC, } \\
\text { IEEE }\end{array}$ & EPA & PUC, FERC \\
\hline $\begin{array}{l}\text { Local DER } \\
\text { Installation Site }\end{array}$ & $\begin{array}{l}\text { UL, CSA, NFPA } \\
\text { (NEC), IEEE, IEC }\end{array}$ & PUC, IEEE & $\begin{array}{l}\text { IEEE, IEC, } \\
\text { NEMA, } \\
\text { EGSA }\end{array}$ & EPA, PUC & PUC, FERC \\
\hline
\end{tabular}

Key:

ANSI - American National Standards Institute

CSA - Canadian Standards Association

EGSA - Engine Generator Systems Association

EPA - Environmental Protection Agency

FERC - Federal Energy Regulatory Commission

IEC - International Electrotechnical Commission

IEEE - Institute of Electrical and Electronic Engineers

NEC - National Electric Code (NFPA 70)

NEMA - National Electrical Manufacturing Association

NERC - North American Electric Reliability Council

NESC - National Electric Safety Code (ANSI C2)

NFPA - National Fire Protection Agency

PUC - Public utility commission (various state and commission rules)

UL - Underwriters Laboratories

These agencies already provide many useful reference documents that may be used for the certification of DER interconnection equipment. Specific references will need to be identified and assessed before being included in certification criteria and requirements, test protocols, and accreditation procedures. An update of the most relevant IEEE interconnection standards is included in the following sections.

\subsection{Role of IEEE Standards in the Interconnection of Distributed Energy Resources}

Several societies and committees within the IEEE play major roles in the interconnection of DER. The key working groups for the interconnection of DER are:

- SCC21 on Fuel Cells, Photovoltaics, Dispersed Generation, and Energy Storage

- SCC22 on Power Quality

- Working Group on Integration of Distributed Resources, Transmission and Distribution Committee of the Power Engineering Society

- Working Group on Emergency and Standby Power Systems in the Industrial Applications Society. 


\subsection{IEEE 1547 DER Interconnection Standard}

There is a critical need for a single document of consensus standard technical requirements for DR interconnection. On June 12, 2003, the IEEE Standards Board addressed this need when it approved IEEE 1547 - 2003 Standard for Interconnecting Distributed Resources With Electric Power Systems, a consensus standard that contains requirements related to performance, operation, testing, safety, and maintenance of interconnections between DR and EPSs. This standard focuses on the technical specifications for, and testing of, the interconnection itself, not on the types of DR technologies. It provides the minimum functional technical requirements that are universally needed to ensure a technically sound interconnection.

The approval of IEEE 1547 will have a significant effect on how the energy industry does business in the future and will influence the way the electrical distribution system will operate - with distributed generators and two-way flow of electric energy. It will help ensure that major investments in the development of DG technologies by the federal government and industry will result in real-world applications. The intent of IEEE 1547 is to define the technical requirements in a manner that can be universally adopted across a number of industries and institutions (e.g., hardware manufacturers, utilities, energy service companies, codes and standards organizations, regulators and legislators, and other interested entities).

Because IEEE 1547 is a standard, it states mandatory requirements. This national standard may be used in federal legislation and rulemaking and state PUC deliberations and by more than 3,000 utilities to formulate technical requirements for interconnection agreements.

\subsection{IEEE 1547 Series of Distributed Energy Resources Interconnection Standards}

IEEE SCC21 continues to develop the remaining 1547 standards. These include:

- IEEE P1547.1 ${ }^{\mathrm{TM}}$ Draft Standard for Conformance Test Procedures for Equipment Interconnecting Distributed Resources With Electric Power Systems

- IEEE P1547.2 ${ }^{\mathrm{TM}}$ Draft Application Guide for IEEE 1547, IEEE Standard for Interconnecting Distributed Resources With Electric Power Systems

- IEEE P1547.3 ${ }^{\mathrm{TM}}$ Draft Guide for Monitoring, Information Exchange, and Control of Distributed Resources Interconnected With Electric Power Systems.

The 1547 series of standards will provide uniform interconnection requirements for distributed generation and storage. The primary effect will be interconnection of customer- or third partyowned generation of less than $10 \mathrm{MW}$. The 1547 series covers inverters and induction and synchronous generators.

See Figure 3 for an overview of IEEE $1547-2003$ and the 1547 series. Other related standards are listed in Appendix E. 


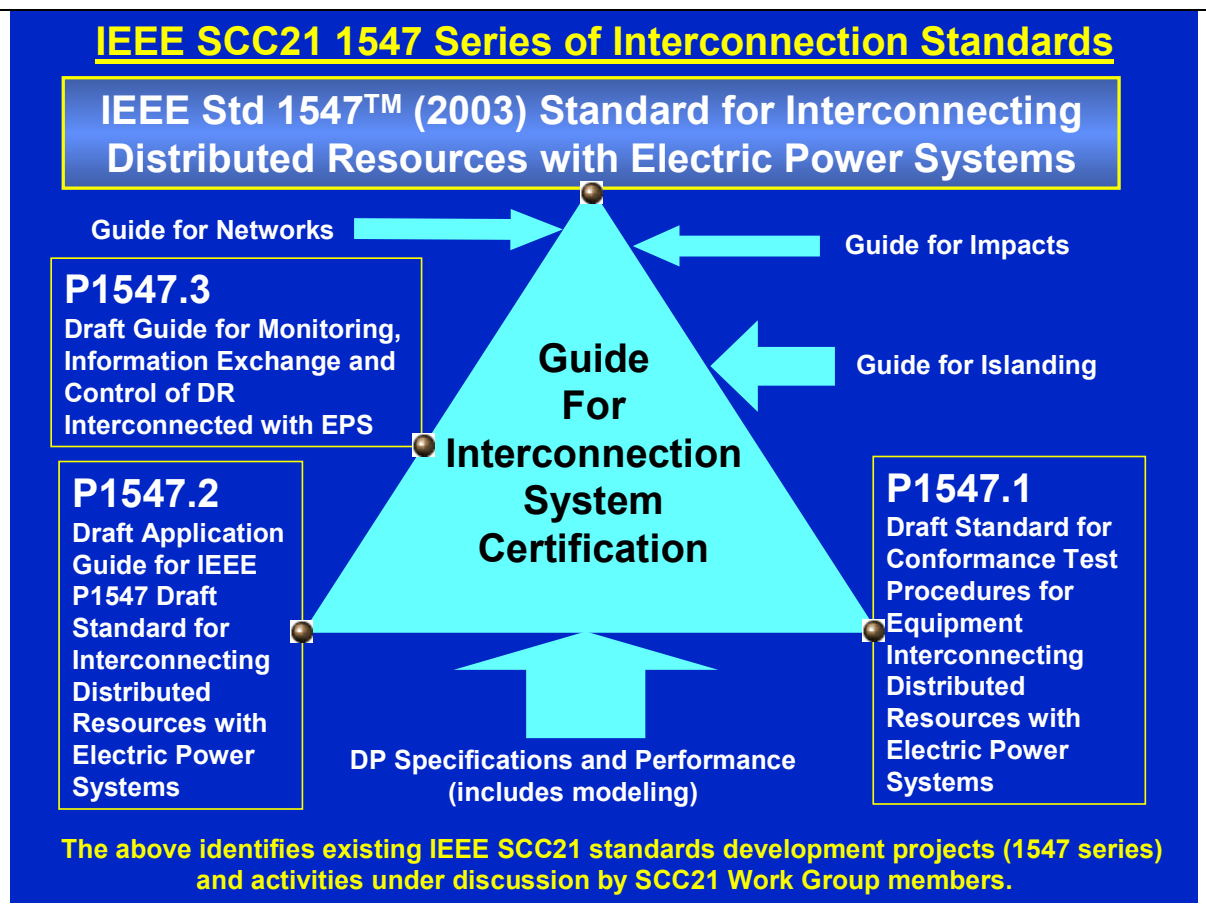

IEEE $1547-2003$ - Scope. This standard establishes criteria and requirements for the interconnection of distributed resources (DR) with electric power systems (EPS).

Purpose. This document provides a uniform standard for the interconnection of DR with EPSs. It provides requirements relevant to the performance, operation, testing, safety, and maintenance of the interconnection.

P1547.1 - Scope. This standard specifies the type, production, and commissioning tests that will be performed to demonstrate that interconnection functions and equipment of a DR conform to IEEE 1547.

Purpose. Equipment that connects DR with an EPS must meet the requirements specified in IEEE 1547. Standardized test procedures are necessary to establish and verify compliance with those requirements. These test procedures must provide repeatable results, independent of test location, and flexibility to accommodate a variety of DR technologies.

P1547.2 - Scope. This guide provides technical background and application details to support the understanding of IEEE 1547 Standard for Interconnecting Distributed Resources With Electric Power Systems.

Purpose. This document facilitates the use of IEEE 1547 by characterizing the various forms of DR technologies and the associated interconnection issues. Additionally, the background and rationale of the technical requirements are discussed in terms of the operation of the DR interconnection with the EPS. Presented in the document are technical descriptions and schematics, applications guidance, and interconnection examples to enhance the use of IEEE 1547.

P1547.3 - Scope. This document provides guidelines for monitoring, information exchange, and control for DR interconnected with EPSs.

Purpose. This document facilitates the interoperability of one or more DR interconnected with EPSs. It describes functionality, parameters and methodologies for monitoring, and information exchange and control. DR include systems in the areas of fuel cells, photovoltaics, wind turbines, microturbines, other distributed generators, and distributed energy storage systems.

For more information, see http://grouper.ieee.org/groups/scc21/dr shared/.

Figure 3. Overview of IEEE SCC21 DER interconnection standards 


\subsection{UL 1741 Standard for Safety}

UL is a nonprofit, independent organization that develops standards for product safety and conducts testing activities based on its own and others' test procedures. One of the standards applicable to the safety of DER is UL 1741. First released in May 1999 under the title Standard for Static Inverters and Charge Controllers for Use in Photovoltaic Power Systems, UL 1741 is being updated as Standard for Inverters, Converters, and Controllers for Use in Independent Power Systems to include requirements that apply to the more broadly defined distributed power sources incorporated under IEEE 1547 . UL 1741 will combine product safety requirements with the utility interconnection requirements developed in the IEEE 1547 standard to provide a testing standard to evaluate and certify DG products. 


\section{Overview of the Certification and Accreditation Web Site}

\subsection{Introduction}

This section describes the DER interconnection certification and accreditation beta Web site developed by EPRI PEAC during the base period of the subcontract.

\subsection{Home Page}

Preliminary Web pages include the home page (Figure 4), which urges DER stakeholders to get involved in the certification effort. It describes the stakeholder working area and provides contact information.

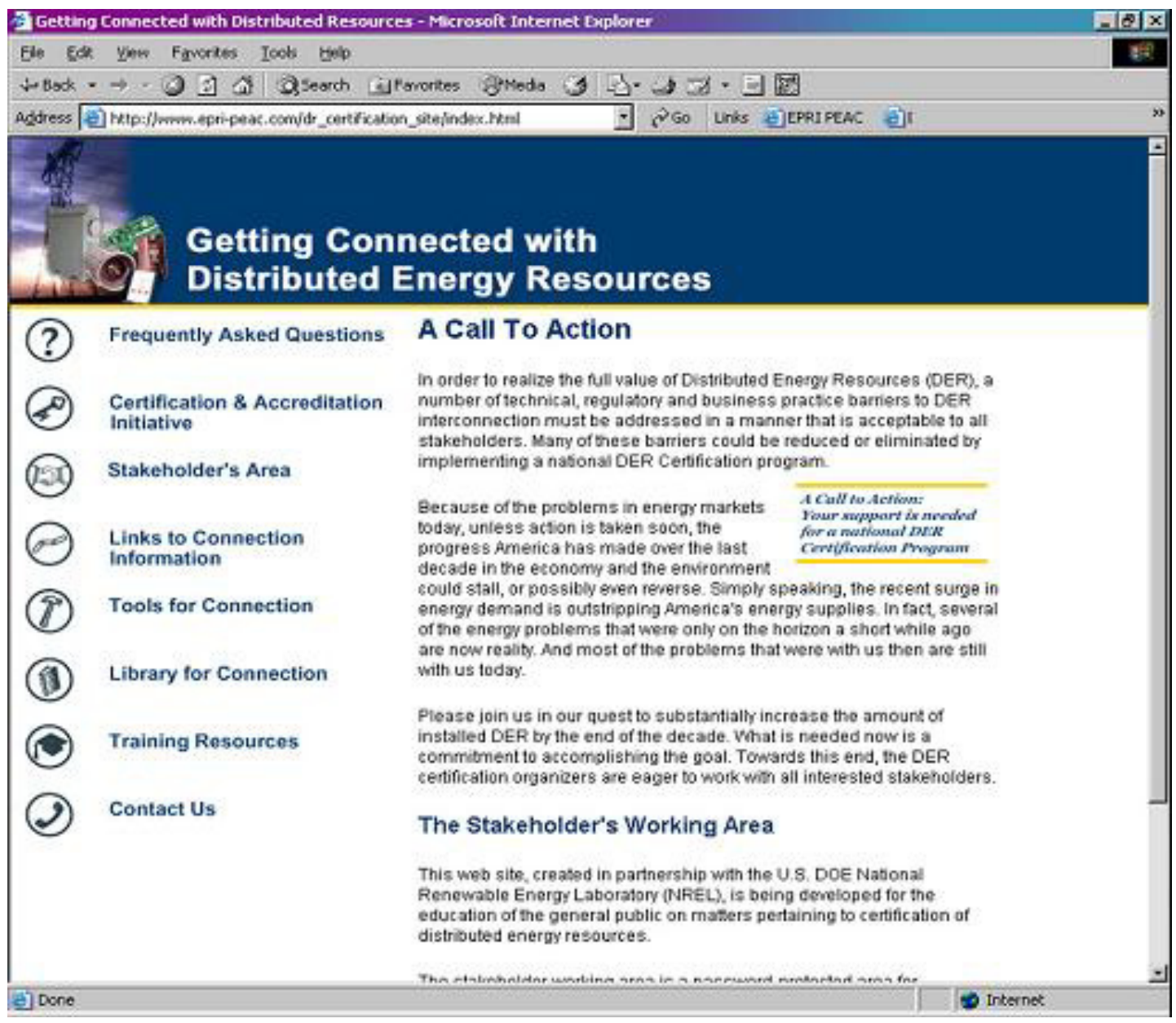

Figure 4. Home page of DER certification Web site

\subsection{Frequently Asked Questions}

The Frequently Asked Questions page describes why DER is important and covers the barriers to interconnecting DER with the grid. It also discusses the measures needed to overcome these barriers. 


\subsection{Certification and Accreditation Initiative}

This area of the Web site contains information about the Certification and Accreditation Initiative.

\subsection{Stakeholder's Area}

Figure 5 shows the opening page of the protected stakeholder's working area. This part of the Web site is for the use of stakeholders who participate in developing the draft model DER certification program. Instructions for gaining access are displayed when the cursor is moved over the stakeholder's area icon on the left menu area.

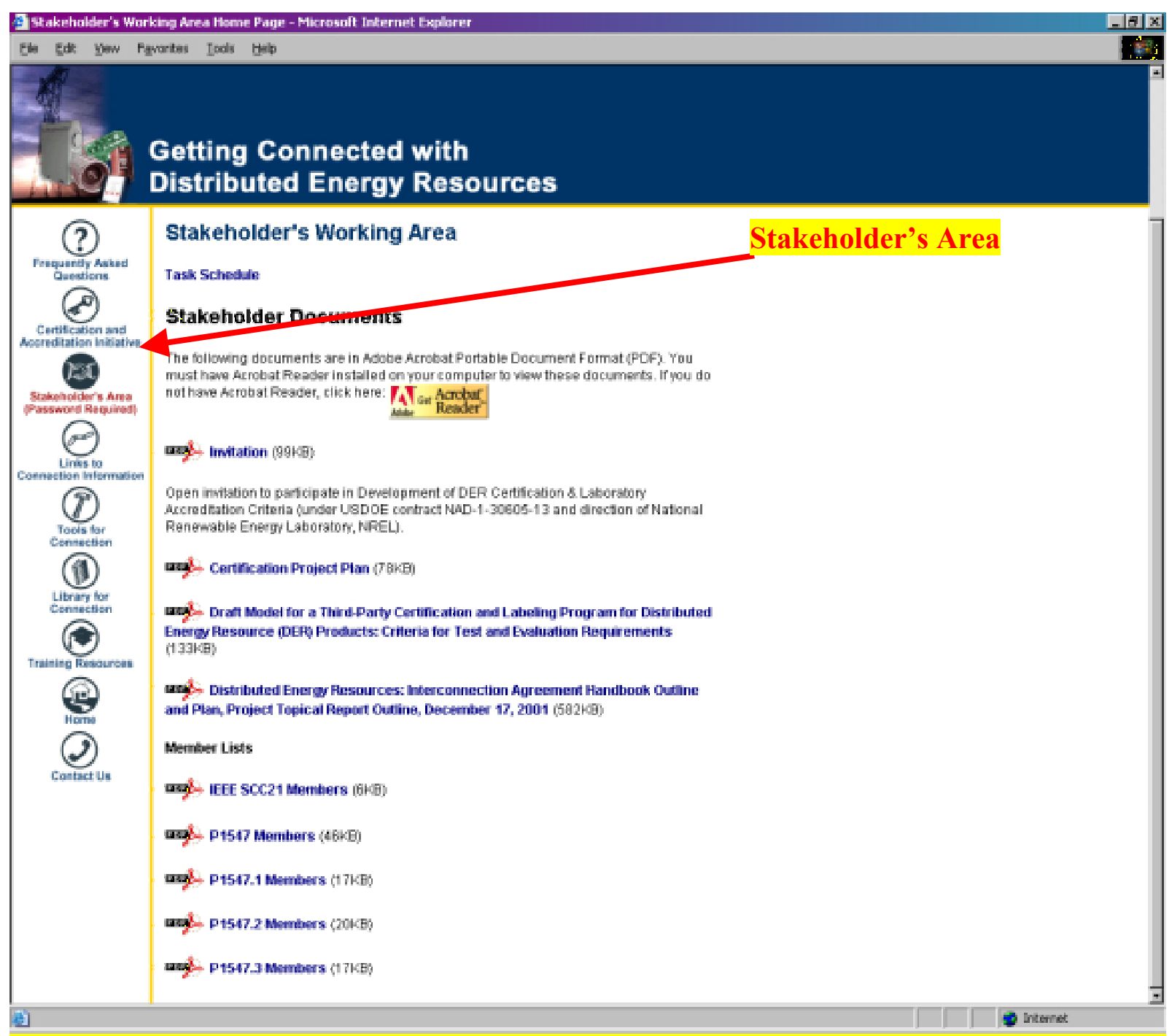

Figure 5. Stakeholder's Working Area of DER certification web site 


\subsection{Links to Connection Information}

As interest in DER and efforts related to DER interconnection continues to grow, the ability to access this widely scattered information from a central location will become increasingly important. A great deal of information about DER interconnection activities is already available. This area of the Web site will consolidate available information by providing convenient links to many of the more important activities related to DER interconnection.

\subsection{Future Plans for Web Site}

Additional pages - including Tools for Connection, Library for Connection, and Training Resources - are under development. These areas will contain information about available tools that will be useful for streamlining the interconnection process, a library of interconnection reference materials, and available training courses. All material on the Web site will be updated and will continue to evolve.

During Option Period 1, information modules will be added to the Web site to build on the base period work. A module on interconnection agreements and one on the interconnection handbook will be added. Also, the site will be updated with the latest technical and regulatory activity in the area of interconnection of DER. These activities are extremely dynamic and are expected to be dynamic for the next several years. It is worthwhile that the latest information be readily available. EPRI PEAC will keep abreast of activities related to DER certification and continue to maintain and enhance the Web-based DER certification resource established in the base period. 


\section{$5 \quad$ Looking Ahead: Where We Go From Here}

The base period activities laid the groundwork for organizing DER stakeholders and forming a collaborative for the establishment of the draft model certification and laboratory accreditation program. The work to date represents only the first steps. Future efforts will further the development of key elements for certification and accreditation of DER interconnection hardware. New standards are expected to provide additional consensus on interconnection details, promote the development of hardware devices, and facilitate efficient connections. Future work will continue to focus on simplifying the process and procedures of interconnection and promoting better compatibility of new DER systems with the electric power infrastructure.

The EPRI PEAC work during the upcoming Option Period 1 will focus on coordinating with manufacturers and conducting extensive preliminary laboratory testing of DER and then conducting the certification pilot. This will also include developing the initial certification test criteria, the certification and accreditation plan, and beta labels and certification reports. The results and lessons learned from these efforts will be translated into draft application-specific test protocols.

Test protocols will be developed as part of the certification program. Using existing test plans and standards combined with information from the certification pilot testing, stakeholder feedback, and years of equipment characterization and test protocol development, EPRI PEAC will initiate the first draft of at least one DER certification test protocol (Figure 6). This initial test protocol will be structured as a living document so it can be revised to reflect inputs from various sources and the experience gained from the actual testing program.

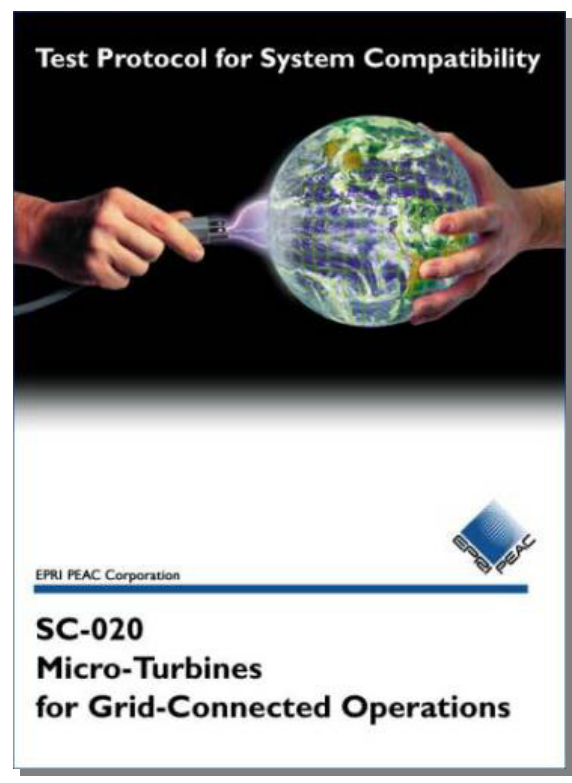

Figure 6. Sample test protocol 
Test protocol documents are necessarily "living documents" that are maintained and become more refined with each new testing experience. The process begins with a basic test plan that addresses the concerns without test specifications. Using the test plan for testing helps refine the procedure, often raises new issues, and provides new observations that must be added to the procedure. After the testing, the test plan is enhanced with the addition of lessons learned, and it becomes the basis for the draft test protocol document that will ultimately evolve into a formal test protocol used for all subsequent certification testing of application-specific DER equipment.

Also during Option Period 1, information modules will be added to the evolving certification Web site. A module on interconnection agreements and one on the interconnection agreement handbook will be added. Also, the site will be updated with the latest technical and regulatory activities related to the interconnection of DER.

From the experience of the pilot testing and stakeholder feedback, EPRI PEAC will complete a draft certification and laboratory accreditation plan that will be reviewed by stakeholders (e.g., a national distributed power coordinating committee) and national accredited testing laboratories for guaranteeing that the equipment meets standard interconnection requirements approved by state regulators. The plan will emphasize how buyers of DER equipment will be able to receive a "grid compatible" certificate from DER manufacturers, which will greatly simplify the grid connection process. State regulatory authorities will be encouraged to require utilities under their jurisdiction to accept the "grid compatible" certificate in lieu of costly engineering studies. The plan will extend well beyond the criteria established in the base period activities. The plan will be developed along the lines of an implementation handbook and include a proposed implementation process as well as drafts of proposed documents necessary for implementation (e.g., a quality system for laboratories, instrumentation calibration, traceability and statistical measurement requirements, model for certification and labeling, testing requirements, organizational documents, bylaws, rules of procedure, and outreach/educational program documents). The document will include sections on definitions, test and evaluation criteria, the evaluation process, reporting, the evaluation team requirements, and suggestions for organization and personnel qualifications.

The concurrent results and considerations of all the above subtasks and tasks will be used to establish the final draft interconnection handbook. The final agreement handbook will build on the existing handbook outline and will be expanded to include a review and analysis of technical and nontechnical requirements related to interconnection or other services supporting interconnection agreements being developed by individual states. Significant groundwork has already been laid by various entities toward the development of rules governing the interconnection of on-site DER.

Beyond Option Period 1, EPRI PEAC will continue to develop and refine these tasks, develop support tools, and identify candidate laboratories for accreditation. See Appendix D for specific tasks and details of EPRI PEAC's upcoming efforts in this endeavor. 


\section{Appendix A: Potential Stakeholders}

A list of more than 30 potential stakeholders - including representatives from the IEEE SCC21 1547 Working Group, the UL 1741 Standards Technical Panel, government agencies, DER manufacturers, utilities, and others - was developed. These potential stakeholders represent the following companies:

Ballard Power Systems

Basler

Bergey Windpower

Bowman

Calnetix Technologies

Capstone

CSA International

Cummins Onan

DTE Energy

Elliott

Endecon Engineering

Enercon Engineering

EPRI-PEAC Corp.

Fuel Cell Energy

GE Distributed Power

H Power

Honeywell Power Systems
IR Energy

New Mexico State University

National Rural Electric Cooperative

Association

National Renewable Energy Laboratory

ONSI

Plug Power

PowerMark Corp.

Puget Sound Energy

Sandia National Laboratories

Siemens Westinghouse Power

Southern California Edison

Steinmetz Engineering

Underwriters Laboratories

Unison Industries

Waukesha Power

Western Resources 
Figure A-1 is the letter of invitation that was sent to individual stakeholders asking them to participate in the development of DER certification \& laboratory accreditation criteria.

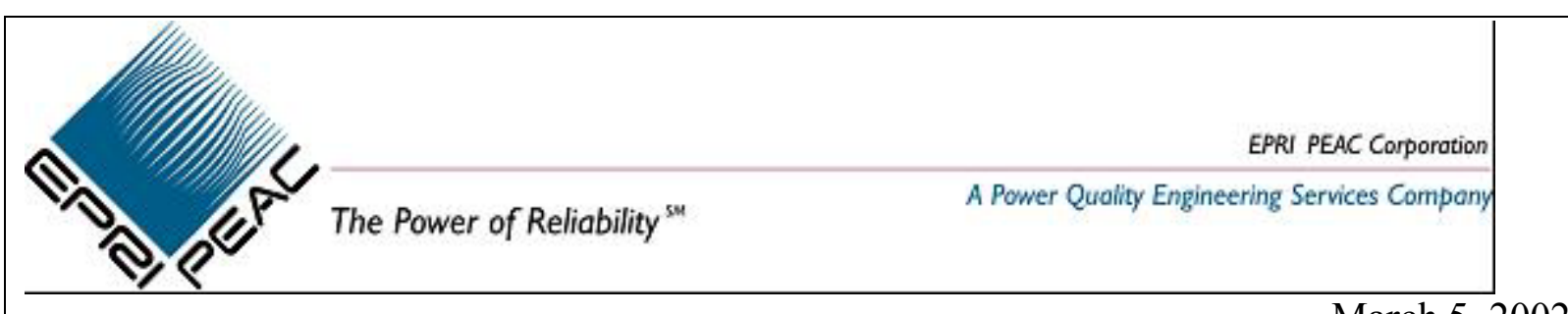

Subject: Invitation to Participate in Development of DER Certification \& Laboratory Accreditation Criteria

Dear (Name),

Per my recent telephone message, this letter is to invite you to join a small group of distributed energy resources (DER) practitioners, equipment manufacturers, policy makers, and other stakeholders in defining the criteria for certification and accreditation of DER. Participants will assist in our development of a roadmap, reference materials, and criteria for pilot certification of DR interconnections. This will entail reviewing, advising, and providing your expertise and constructive feedback along the way.

This certification and accreditation effort is being organized and coordinated by EPRI PEAC, in support of DOE's Distributed Power Program, as one of the DOE/NREL Distributed Power System Integration Research and Development activities. The objective is to help promote the growth of distributed power in the U.S. by simplifying the efforts required to connect DR with local power grids. The vision is for participants to help develop appropriate test criteria and procedures for evaluating, and "certifying" DR equipment to be compatible for grid connection, thereby simplifying interconnection agreements between system operators, independent power producers, and distribution companies.

We have drafted a road map (dated February 20, 2002) for this effort and attached it for your review. The certification roadmap builds on, and includes, meaningful, relevant, and existing standards and certification programs as a basis, including those from industry and from a national and international perspective. The perceived strengths and weaknesses of these existing programs will be examined to identify latent certification and accreditation problems and proposed solutions for moving forward. The result will be development of criteria and procedures, and the development plan for the structure and function of DR product certification and laboratory accreditation.

We intend to create an oversight board, solicit your inputs on testing and reporting procedures, and to develop test protocols that describe rationale and expected results. Also technical transfer mechanisms, such as a web site, problem-solving forums, web-based training, and organizational workshops will be set up. This invitation to you is aimed at identifying key stakeholders who understand the importance of this effort and who are willing to participate. You can obtain additional information at our special web site that has been created to facilitate communications related to this effort (see www.epripeac.com/dr_certification_site/index.html). If you are interested in working with us, or would simply like to further discuss the effort, please contact Ralph Ferraro (as noted below).

We look forward to hearing from you.

Sincerely,

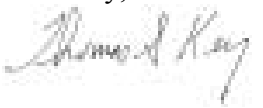

Thomas S. Key

EPRI PEAC

Tel: 865-218-8082

Tkey@epri-peac.com
Ralph J. Ferraro, PE

EPRI PEAC Consultant

Tel: 865-218-8083

Rferraro@epri-peac.com

Figure A-1. Letter of invitation sent to stakeholders 


\section{Appendix B: Test and Evaluation Criteria for Certification of DER Interconnection (DER-3)}

\section{B.1 Introduction}

This is one of a series of discussion draft documents that collectively will evolve to define the criteria and requirements of a DER interconnection certification and labeling program. At this point, none of the discussion draft documents has been reviewed by stakeholders.

This document will include descriptions of the DR certification and accreditation documents, the overall procedure, the general test and evaluation criteria (modeled after PV-3), and the technical criteria specific for grid interconnection (modeled after PV-3.3). DER-3 will also describe possible application-specific protocols for testing and labeling, focusing solely on certifying interconnections and accrediting laboratories to provide the interconnection certifications.

The test methods and procedures chosen for this purpose have been developed either as national or international consensus standards (e.g., by the American Society for Testing Materials, IEEE, ANSI, UL, IEC, EGSA), by other reputable technical organizations, or in relevant scientific texts or journals. DER-3 provides general requirements; specific testing and evaluation requirements may need to be provided in individual subdocuments. Each specific subdocument may be written to cover a unique DER interconnection system component or system type (e.g., utility, industrial, commercial, or residential) that may involve testing.

These proposed test methods and procedures represent the minimum testing requirements for a DER product certification and labeling program. In addition, these proposed test procedures and the concomitant equipment and facilities requirements represent the minimum test capabilities against which laboratories will be evaluated for testing in support of a DER interconnection certification and labeling program.

\section{B.2 Purpose and Scope}

The purpose of this document is to delineate the proposed testing and evaluation requirements for a DER system interconnection certification and labeling program. This document provides general requirements; unique testing and evaluation requirements may need to be provided in individual subdocuments. Each specific subdocument may be written to cover a unique DER interconnection system component or system type (e.g., utility, industrial, commercial, or residential) that may involve unique testing.

The test procedures to be provided in the subdocuments represent the minimum capabilities against which laboratories will be assessed and accredited in accordance with testing in support of the DER interconnection system certification and labeling program.

This document provides the minimum proposed general requirements with which laboratories will comply to demonstrate their competence to test DER interconnection products. It also provides guidelines for the management of the testing laboratory. 
The relevant new definitions pertaining to testing, calibration, verification, and certification contained in future DER documents should be incorporated by reference and are not repeated.

\section{B.3 Acronyms Used}

A2LA American Association for Laboratory Accreditation

ANSI American National Standards Institute

ASCII American Standard Code for Information Exchange

ASQC American Society of Quality Control

ASTM American Society for Testing Materials

DNP digital network processing

IEEE Institute of Electrical and Electronic Engineers

IEC International Electrotechnical Commission

ISO international standards organization

ISO independent system operator

IPP independent power producer

NIST National Institute of Standards and Technology

NVLAP national voluntary laboratory accreditation program

RTO regional transmission organization

RTU remote terminal unit

SCADA supervisory control and data acquisition

UCA Utility Communication Architecture

UL Underwriters Laboratories

\section{B.4 Procedural Definitions}

Authority having jurisdiction (AHJ) (electrical): An entity that interprets the requirements of electrical codes and standards and approves electrical equipment for use.

\section{AHJ field report:}

Definition 1: A written report that verifies that a piece of electrical equipment or an installation is acceptable for use.

Definition 2: A written report that describes the reasons electrical equipment does not comply with a mandatory standard. It may include recommendations to achieve equivalent safety criteria.

Certification: The procedure by which written assurance is given that a product or service conforms to a specification. A third-party certification is one that is rendered by a technically and otherwise competent body not controlled by the producer or the buyer.

Examination: A process performed by a person qualified to evaluate whether electrical equipment is free from recognized hazards and meets code requirements. 
Certification program: The system that relates to specific products, processes, or services to which the same particular standards and rules, and the same procedure, apply. Such a program uses or is operated by a third-party inspection or testing body or organization and authorizes the use of controlled certification marks or certificates of conformity as evidence of conformity.

Certification body: An impartial body or organization that possesses the necessary competence to develop, promulgate, finance, and operate a certification program and conduct certifications of conformity. Note: A certification body may operate its own testing and inspection activities, or it may oversee these activities carried out on its behalf by other bodies, e.g., by an independent testing laboratory.

Conformity: Fulfillment by a product, process, or service of specified requirements.

Conformity evaluation: Systematic examination of the extent to which a product, process, or service fulfills specified requirements.

Conformity surveillance: Evaluation for conformity to determine the continuing conformity with specified requirements.

Certification mark: The sign or symbol owned and controlled by the certification body that is used exclusively by the third-party certification program to identify products or services as being certified and is registered as a certification mark with the U.S. Patent Office under the Trade Mark Act of 1946.

Certificate of conformity: A tag, label, nameplate, or document of specified form and content, affixed or otherwise directly associated with a product or service on delivery to the buyer, attesting that the product or service is in conformity with the requirements of the certification program (e.g., with the referenced standards and specifications).

Inspection: Evaluation for conformity by measuring, observing, testing, or gauging the relevant characteristics as required by a specification or standard.

Label: A nationally recognized testing laboratory label, symbol, or other identifying mark that is affixed to equipment or materials.

Listed: Electrical equipment and materials listed by an organization concerned with product evaluation that have been examined against designated standards and found to be suitable for use in specified operations. The means of identifying electrical equipment may vary among listing organizations, some of which do not recognize equipment as listed unless it is also labeled. AHJ should use the system employed by the listing organization to identify a listed product. 
License (for certification): Document, issued under the rules of a certification program, by which a certification body grants to a person, manufacturer, or producer the right to use the certificates or marks of conformity for its products, processes, or services in accordance with the rules of the relevant certification program.

Licensee (for certification): Person, manufacturer, or producer to which a certification body has granted a license.

Producer: The manufacturer, distributor, supplier, or other party providing the product or service to be purchased and employed by a user. The producer is responsible for assuring conformity with all requirements of the certification program.

Standard: A prescribed set of conditions and requirements, established by authority or agreement, for continuous application. It takes the form of a document containing a set of conditions to be fulfilled or an object of comparison. For the purposes of this document, the provisions as defined and used in this document shall be such as to be suitable to and capable of certification.

Tests: Technical operations that consist of the determination of one or more characteristics of a given product, process, or service according to a specified procedure.

Testing: Actions, or the process, of carrying out one or more tests.

Testing/Inspection body (third party): An organization (if a testing body, a laboratory) that possesses the necessary technical competence and that is other than one operated or controlled by a manufacturer, supplier, or buyer (user) of a certified product or service in that it has no organizational, financial, or commercial involvement with the producer or buyer that might pose a potential conflict of interest. Note: An inspection body is an organization, often organized separately from the testing laboratory and often a functional arm of the certification body (whether an organizational or a subcontracted entity), that performs initial inspections of a manufacturer's or producer's operations, including any subsequent surveillance procedures that may be required.

\section{B.5 Technical Definitions (Initial Discussion Draft - Not Yet Reviewed)}

Area EPS: An electric power system (EPS) that is capable of serving two or more Local EPSs. Typically, the Area EPS enjoys benefits such as the ability to occupy public rights-ofway and cross property boundaries and is subject to regulations such as, but not limited to, obligations to serve that Local EPSs are not. 


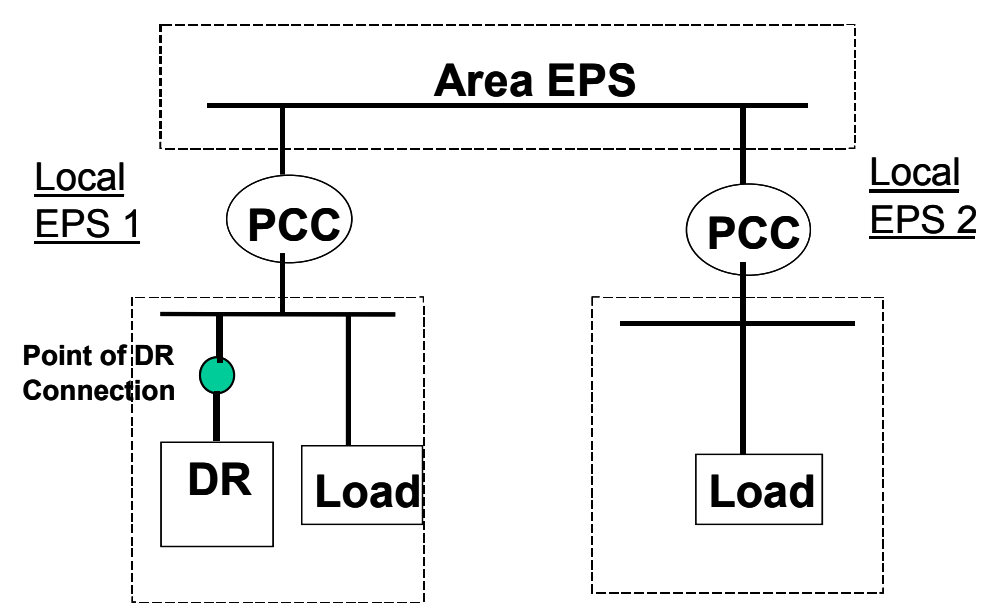

Figure B-1. Area EPS

Dedicated transformer: A transformer installed between the Area EPS and the Local EPS that serves only the DR and attached loads, if any.

Directional-power relay: A relay that operates on a predetermined value of power flow in a given direction or upon reverse power so that, when used with DR in a nonexport configuration, it will prevent power flow into the Area EPS.

DISCO: Distribution company or distribution wires company.

Distributed generation (DG): Electric generation facilities connected to an Area EPS through a PCC; a subset of DR.

Distributed resources (DR): Sources of electric power that are not directly connected to a bulk power transmission system. DR include both generators and energy storage technologies.

Definition 1: A generic term for small sources of electric power that are not part of a large central power source. Individual sources may be associated with an electric utility grid or with an electric power consumer. They may be connected to the system for reliability, voltage control, base load operation, peak load reduction, energy recovery, disturbance reduction, or standby service.

Definition 2: Integrated or standalone use of electricity generation, storage, distribution, and end-use or demand-side management technology methods by utilities, utility customers, and third parties in locations that benefit the electric system, specific customers, or both. As applied specifically in this report, the term DR refers only to the generation aspect of this definition and is synonymous with the term distributed generation.

Definition 3: Sources of electric power that are connected to the distribution system. They may be connected to the system for reliability, voltage control, base load operation, peak load reduction, energy recovery, disturbance reduction, or standby service. 
Distributed storage: Energy storage distribution within the EPS.

DR unit: A single generating device applied at a specific location.

Electric power system (EPS): Any facility that allows electric power to be delivered to a load, regardless of ownership. This may include a generation unit.

Electrical equipment: Equipment that uses electrical energy for electronic, electromechanical, or chemical operations; heating; lighting; or similar purposes. Electrical equipment includes equipment used in laboratory R\&D as well as utility, facility, and shop equipment.

Fault: A physical condition that causes a device, a component, or an element to fail to perform in a required manner, e.g., a short circuit, a broken wire, or an intermittent connection (IEEE 100, The Authoritative Dictionary of IEEE Standards Terms).

Harmonic distortion: Continuous distortion of the normal sine wave, typically caused by nonlinear loads or inverters, measured in total harmonic distortion.

Induction generator: An induction machine, when driven above synchronous speed by an external source of mechanical power, used to convert mechanical power into electric power (IEEE 100, The Authoritative Dictionary of IEEE Standards Terms). Note: Induction generators may draw lagging reactive power from the EPS.

Integration of DR: Integration considers the operation of the entire EPS, how this system is affected by DR, and how to maximize the strategic value of these resources in the system. It is intended to have a broader meaning than simply interconnection of DR at a single point in the power system.

Interconnection: The result of the process of adding a DR to an EPS in a safe, reliable manner, maintaining appropriate levels of protection and performance.

Interconnection Equipment: Devices that provide appropriate control and protective functions to meet the prescribed conditions for connecting DR to the EPS.

Interconnection System: The collection of devices and packages that provide appropriate control and protective functions to meet the prescribed conditions for connecting DR to an Area EPS.

Inverter: A machine, device, or system that changes direct-current power to alternatingcurrent power.

Island: A condition in which a portion of the Area EPS is energized by one or more distributed generators through the point(s) of common coupling while electrically separated from the rest of the Area EPS. 
Island (intentional): A preplanned island condition in which distributed generators and a portion of the Area EPS remain energized through the PCC. Potential safety and reliability issues have been addressed prior to the islanding.

Island (unintentional): An unplanned island condition in which one or more distributed generators and a portion of the Area EPS remain energized through the PCC. Safety and system reliability problems may exist.

Local EPS: An EPS contained entirely within a single premises.

Network (primary distribution system): A system of alternating-current distribution in which the primaries of the distribution transformers are connected to a common network supplied from the generating station or substation distribution buses (IEEE 100, The Authoritative Dictionary of IEEE Standards Terms).

Network (grid): See Secondary network.

Network (spot): See Spot network.

Network protector: An assembly comprising a circuit breaker and its complete control equipment for (1) automatically disconnecting a transformer from a secondary network in response to predetermined electrical conditions on the primary feeder or transformer and (2) connecting a transformer to a secondary network through manual control or automatic control responsive to predetermined electrical conditions on the feeder and the secondary network. Note: The network protector is usually arranged to automatically connect its associated transformer to the network when conditions are such that the transformer, when connected, will supply power to the network and to automatically disconnect the transformer from the network when power flows from the network to the transformer (IEEE 100, The Authoritative Dictionary of IEEE Standards Terms).

Penetration factors: The DR capacity interconnected in the power system relative to other measures of feeder or service capacity. For example, the penetration factor relative to the total peak load on the feeder is determined by dividing the aggregate capacity in kilovolt-amperes of all DR on the feeder by the peak feeder load (kilovolt-amperes) as shown below:

Penetration factor $_{\text {Total feeder load }}=\frac{\text { Aggregate DR rating on feeder in } \mathrm{kVA}}{\text { Peak load on feeder in } \mathrm{kVA}}$

Phase-sequence voltage relay: A relay that functions on a predetermined value of polyphase voltage in the desired phase sequence (IEEE 100, The Authoritative Dictionary of IEEE Standards Terms).

Point of common coupling (PCC): The point at which a Local EPS is connected to an Area EPS.

Point of DR connection: The point at which the DR unit is electrically attached to an EPS. 
Point of nearest adjacent customer tap: The location on the EPS at which the nearest electric customer independent of the DR site is connected to the power system. This may be on the primary or secondary system. As an example, in the case in which a 25-kVA distribution transformer serves a group of four houses, this would often involve some common secondary conductors from which service drops are tapped for the individual customers (houses). If one of these four customers has a DR system, the point of nearest adjacent customer tap for this situation would be the tap point of the service drop wires for the customer electrically nearest the DR site. In typical situations, this could be anywhere from 25 to 100 meters upstream of the PCC of the DR site. An example of a situation in which the point of nearest adjacent customer tap is on the primary is when the distribution transformer serving the DR site is dedicated to that customer (in other words, there are no other customers on that secondary). In that case, the point of nearest adjacent customer tap would typically be at the primary right where the transformer is connected. However, the point of nearest adjacent customer tap could be even farther upstream if there are no other distribution transformers tapped from that primary in that vicinity. An example is a one-fourth-mile primary branch that serves only the DR site. In this case, the point of nearest adjacent customer tap is where the one-fourth-mile branch connects to the main primary feeder.

Power factor: Ratio of real to total apparent power (kilowatts/kilovolt-amperes) expressed as a decimal or percent (IEEE 100, The Authoritative Dictionary of IEEE Standards Terms).

Primary distribution feeder: A feeder operating at primary voltage supplying a distribution circuit. Note: A primary feeder is usually considered as that portion of the primary conductors between the substation or point of supply and the center of distribution (IEEE 100, The Authoritative Dictionary of IEEE Standards Terms).

Reactive power: Reactive power, Q, is defined as the square root of the square of the apparent power, S, minus the square of the active power, P. Reactive power is developed when there are inductive, capacitive, or nonlinear elements in the system. It represents energy that cannot be extracted from the system but can cause increased losses and excessive voltage peaks.

Regulation ratio: A term that compares the utility system's available fault current at the planned interconnection point of the DER unit with rated output of the DER unit.

Relay: An electrically controlled, usually two-state device that opens and closes electrical contacts to effect the operation of other devices in the same or another electric circuit (IEEE). Note: For DER, the device or devices are used to perform a specific function protecting equipment on an EPS.

Secondary distribution feeder: A feeder operating at secondary voltage supplying a distribution circuit (IEEE 100, The Authoritative Dictionary of IEEE Standards Terms).

Secondary network: A system of alternating current distribution in which the secondaries of the distribution transformers are connected in a grid, typically energized at the customers' utilization voltage, to serve multiple loads. 
Self-commutated: An inverter in which the commutation elements are included (IEEE 100, The Authoritative Dictionary of IEEE Standards Terms).

Simulated utility: A piece or assembly of variable frequency and variable voltage test equipment used to simulate a normal utility source in certification testing of DR.

Spot network: A small network, usually at one location, consisting of two or more primary feeders with network units and one or more load service connections (IEEE 100, The Authoritative Dictionary of IEEE Standards Terms).

Static power converter: An electronic device with control, protection, and filtering functions used to interface an electric energy source with an electric utility system. Sometimes referred to as power conditioning subsystems, power conversion systems, solid-state converters, or power conditioning units (IEEE 100, The Authoritative Dictionary of IEEE Standards Terms).

\section{Stiffness ratio:}

Definition 1: Compares the ratio of the utility system's available fault current at the DR location PCC without the DR with the maximum rated output current of the DR unit at the PCC.

\section{Stiffness ratio $=$ Ifault/I DR-output}

Definition 2: Compares the total of the short circuit kilovolt-amperes of the utility system plus the DR at the PCC with the DR short circuit kilovolt-amperes.

Stiffness ratio $=(\mathrm{SC} k \mathrm{kA}$ Area EPS $+\mathrm{SC} \mathrm{kVA} \mathrm{DR}) / \mathrm{SC} \mathrm{kVA} \mathrm{DR}$

$\mathrm{SC} \mathrm{kVA}$ (Area EPS) = the short circuit contribution in $\mathrm{kVA}$ of the area EPS

$\mathrm{SC} \mathrm{kVA}(\mathrm{DR})=$ the short circuit contribution in $\mathrm{kVA}$ of the DR

Note: The stiffness ratio is calculated at the PCC except when there is a transformer dedicated to one customer. In this case, the stiffness ratio is calculated on the high-voltage side of the dedicated transformer.

Synchronous generator: A synchronous alternating current machine that transforms mechanical power into electric power. (A synchronous machine is one in which the average speed of normal operation is exactly proportional to the frequency of the system to which it is connected (IEEE 100, The Authoritative Dictionary of IEEE Standards Terms).

Test (field): (A) Tests made on operating systems usually to investigate the performance of switchgear or its component parts under conditions that cannot be duplicated in the factory. Note: Field tests are usually supplementary to factory tests and therefore may not provide a complete investigation of capabilities. (B) Tests made after the assembly has been installed at its place of use (IEEE 100, The Authoritative Dictionary of IEEE Standards Terms). 
Test (periodic): Test performed at scheduled intervals to detect failures and verify operability (IEEE Std. 100 IEEE 100, The Authoritative Dictionary of IEEE Standards Terms).

Transfer switch: A device for transferring one or more load conductor connections from one power source to another (IEEE 100, The Authoritative Dictionary of IEEE Standards Terms).

Voltage-restrained overcurrent relay: A protective relay in which the pickup and overcurrent tripping times are affected by the voltage. This type of relay is used in applications for which it is desirable to have the relay change to a lower pickup current and faster tripping curve during conditions in which the voltage is lower than normal.

\section{B.6 Test and Evaluation Criteria}

Specific test and evaluation criteria may be provided in the subdocuments. In general, the objectives of the interconnection are to address the following interconnection concerns:

- Safety - DER should not create any undue safety hazard for utility personnel, customers, or the public.

- Utility system voltage quality - DER will not cause objectionable power quality, voltage regulation, or voltage flicker on the utility system for any customers.

- Service reliability - DER equipment should not degrade the reliability of the power system.

- Utility system overcurrent devices - DER will not interfere with the operation of the utility system overcurrent protection equipment.

- Damage to utility and customer equipment - DER units should not cause damage to utility and customer equipment during steady-state and faulted system operating conditions.

- Service restoration - The DER unit will not interfere with restoration of power on the utility system.

- Utility system operating efficiency - Units will operate at power factors and at generation density levels that maintain utility system efficiency.

Laboratories intending to participate in the DER system certification and labeling program will select one or more of these documents and obtain the necessary accreditation.

Considering the large variety of DER hardware types and interconnection scenarios, it is anticipated that application-specific test protocols will be developed to accomplish the desired DER system tests. 
To initiate the test and evaluation criteria "thinking process," the following paragraphs are examples of generic criteria for a DER system intended for grid-tied applications. These criteria came from the proceedings of 1547 standard development as well as several recent research reports on the subject of interconnection and integration. ${ }^{\mathrm{A}-1, \mathrm{~A}-2}$

With the approval of IEEE 1547 Standard for Interconnecting Distributed Resources With Electric Power Systems, the minimum requirements for interconnection of DR with EPSs are established. It provides uniform standards for interconnection and requirements relevant to the performance, operation, testing, safety, and maintenance of the interconnection.

Criteria for system approvals are based on applicable codes and standards and consistency with industry-accepted design practices. Evidence to support these criteria must be contained in the DER equipment supplier's system manual and other design documentation provided by the manufacturer. General criteria include:

- Conformance of the overall electrical design and specified installation methods with all relevant sections of the National Electrical Code

- Evidence of applicable product listings for major components from UL or other recognized laboratories. Panels and inverters must meet the UL 1741 standard for Inverters, Converters, and Controllers for Use in Independent Power Systems or equivalent standards.

\section{B.7 Evaluation Process}

\section{B.7.1 DER Interconnection Documentation Review}

At a minimum, this documentation should include:

System description and specifications

Parts and source lists for equipment supplied and not supplied with package

Electrical diagrams and schematics

Mechanical drawings

Installation and checkout procedures

Operation, maintenance, and troubleshooting instructions

Owners manuals for individual major components

Information about how system performance monitoring is accomplished

Warranty information for components and the complete system.

If any of these items are not provided in the documentation, written justification must be submitted to explain the deficiency. The evaluation team will review the explanation to determine whether to wave the requirement or deny certification.

\footnotetext{
A-1 Engineering Guide for Integration of Distributed Generation and Storage into Power Distribution Systems. EPRI Report 1000419. December 2001.

A-2 Technology Assessment of Interconnection Products for Distributed Resources: 2001 Update. EPRI Report 1003969.
} 


\section{B.7.2 Distributed Energy Resources Interconnection Electrical Design Evaluation}

A principal concern of this evaluation process is establishing that the system electrical design is safe and compliant with the National Electrical Code. Sufficient detail must be supplied in the documentation to show the recommended method of complying with the electrical code. At a minimum, supplier's documentation and drawings should specify or identify:

- Appropriate types, sizes, and locations of all AC and DC system conductors based on temperature, location, and length of wire run

- Types and ratings for conduit and wire ways to be used in the installation based on temperature, location, and conductor fill

- $\mathrm{AC}$ and $\mathrm{DC}$ voltage drop limitations and conductors required for a given length

- Ratings and locations for required $\mathrm{AC}$ overcurrent and disconnect devices

- Ratings and locations for required DC overcurrent and disconnect devices

- Types, ratings, and locations for junction boxes

- Requirements for equipment and system grounding

- Requirements for surge suppression equipment

- DER mechanical design evaluation.

At a minimum, the system manual documentation and drawings should include the information specified below. Independent laboratory test results or certification from a licensed engineer should be provided for mechanical loads on the DER system structures.

\section{General}

At a minimum, suppliers' documentation and drawings should specify or identify:

- Hardware for mechanical assembly of the DER system components

- Procedures required for assembling the DER system

- Hardware for making any structural attachments

- Details of how the design avoids environmentally incompatible materials and contact of dissimilar metals

- Safety considerations for installing the DER system

- Methods to ensure unrestricted air flow around the DER system

- Methods for accessibility and maintaining the DER system. 


\section{Interconnection Equipment}

At a minimum, any inverters and power processing hardware will:

- Comply with UL 1741 or equivalent product listing, including all provisions for "utility interactive" inverters, including anti-islanding.

- Be accompanied by a user manual with operating and troubleshooting instructions

- Include visual indicators of operating conditions and performance

- Provide appropriate ratings of source circuit supplementary overcurrent devices

- Include packaging that meets requirements for outdoor installations

- Provide acceptable voltage operating window for the specified equipment under operating extremes

- Provide means of locking accessible disconnects.

\section{Utility Interconnection}

At a minimum, the utility interconnection should comply with accepted industry standards and include identification of the equipment and methods used to interconnect the DER system with the utility grid. Interconnection information should:

- Comply with, for example, IEEE 929-2000 IEEE Recommended Practice for Utility Interface of Photovoltaic Systems

- Provide guidelines for permitting, inspections, and interconnection agreements

- Describe options and means for point of utility interconnection

- Describe overcurrent and disconnect devices required at the point of connection.

\section{B.8 Reporting}

\section{B.8.1 Evaluation Report}

The evaluation report will cover all the evaluation criteria and state how those criteria were met by the certified system. Any deficiencies or areas of concern raised by the evaluation team will be documented in the report. The results of this report will be made available only to the testing laboratory and the DER manufacturer.

\section{B.8.2 Evaluation Difficulties}

When a DER system cannot be subjected to some aspect of an evaluation required by this document, the circumstances will be documented and reported. It will be up to the testing laboratory to resolve such issues with the DER manufacturer, which may require the manufacturer to state the ramifications in the system documentation.

\section{B.8.3 Denial of Certification}

If the system under evaluation does not satisfy the criteria outlined in this document, the laboratory will give the DER manufacturer written notice with the reasons for denial. A manufacturer that wishes to contest the findings of the laboratory may file with the testing laboratory a written request for review. The testing laboratory will appoint a laboratory complaint review board, which will reconsider the information on file. Based on the review board's findings, the testing laboratory will affirm, modify, or reverse the initial decision and inform the DER manufacturer. 


\section{B.8.4 Removal of Certification}

\section{B.8.4.1 Manufacturer-Initiated}

A party that has been issued a certification for a DER product may voluntarily terminate the certification by giving written notice to the testing laboratory. The note will state the effective termination date and the reasons for termination.

\section{B.8.4.2 Laboratory-Initiated}

A laboratory may revoke or suspend certification for a DER system it evaluated in the event of:

- Material misrepresentation in the application for evaluation and certification

- Misrepresentation that one DER system certification applies to another system that has not been approved

- Failure to comply with a condition of certification or product labeling

- Failure to correct a discrepancy that is detected by the laboratory after initial laboratory approval (the supplier will be given 30 days to make corrections).

The procedure for revoking certification will conform to the process for denial of certification specified above.

\section{B.8.5 Evaluation Team Requirements}

It is important that the evaluation team possess the full range of the following requirements if it is to complete a comprehensive system review. This will often require consulting engineers for specific review tasks.

A team leader must be appointed for each system evaluation so questions about the evaluation can be addressed by a single contact. Among the evaluation team members, the following background, experience, and expertise must be represented:

- 5 years experience designing and installing DER systems

- 5 years experience testing and evaluating fielded DER systems

- Participation in standards development for DER components and systems (such as participation in Article 690 Technical Review Committee or IEEE SCC21)

- Experience working with local code jurisdictions to interpret the NEC and building codes

- Publication of technical papers or articles about DER system design and installation

- Specialized experience in each area relevant to DER system design and evaluation:

○ Mechanical design

- Structural design

- Electrical design

$\circ$ Electronic power conditioning and inverter operation

- Utility interconnection and power quality impacts/mitigation approaches

o Performance monitoring. 
Meeting the full extent of these competencies will typically require a team of three to five members. An additional three to five specialized engineers may be required for consultation on special issues on an as-needed basis. Each of the members must be listed and a description written of the competencies the member supports. Resumes of evaluation committee members are required for reference.

\section{B.8.6 Individual Requirements}

Each team member must meet one or more of the listed requirements. Resumes for each member, detailing their relevant experience, will be held on file at the evaluating laboratory.

Each member will sign a nondisclosure agreement with the testing laboratory.

For each system evaluated, each member will sign a statement that he or she has no conflict of interest that might affect the evaluation of the system in question.

\section{B.8.7 Laboratory Organization and Personnel}

This section will provide an overview of the organization, structure, and functional requirements for personnel to effectively manage and operate a DER product certification laboratory and meet the requirements of the future DER document "Criteria for a Model Quality System for Laboratories Engaged in Testing DER Products."

Economics will dictate that the staff be kept small yet large enough to perform all tasks required by the referenced documents. Because of the technical nature of the testing and the stringent requirements for documentation and conformance to standards, the staff will need to be multidisciplinary with extensive cross-training.

\section{B.8.8 Organization}

A simplified organization chart for operation of a certification laboratory is shown in Figure B-2. The number of people needed to fill each functional box will depend on the level of DER product testing and other related businesses operated by the laboratory. During the formative stages, two or three carefully selected staff members should be adequate to perform all tasks. During this period, certain functions, such as periodic equipment maintenance and facility requirements, will likely be contracted. The initial staff, being limited to a few individuals, will have to be highly trained, multidisciplined, and quite versatile. 


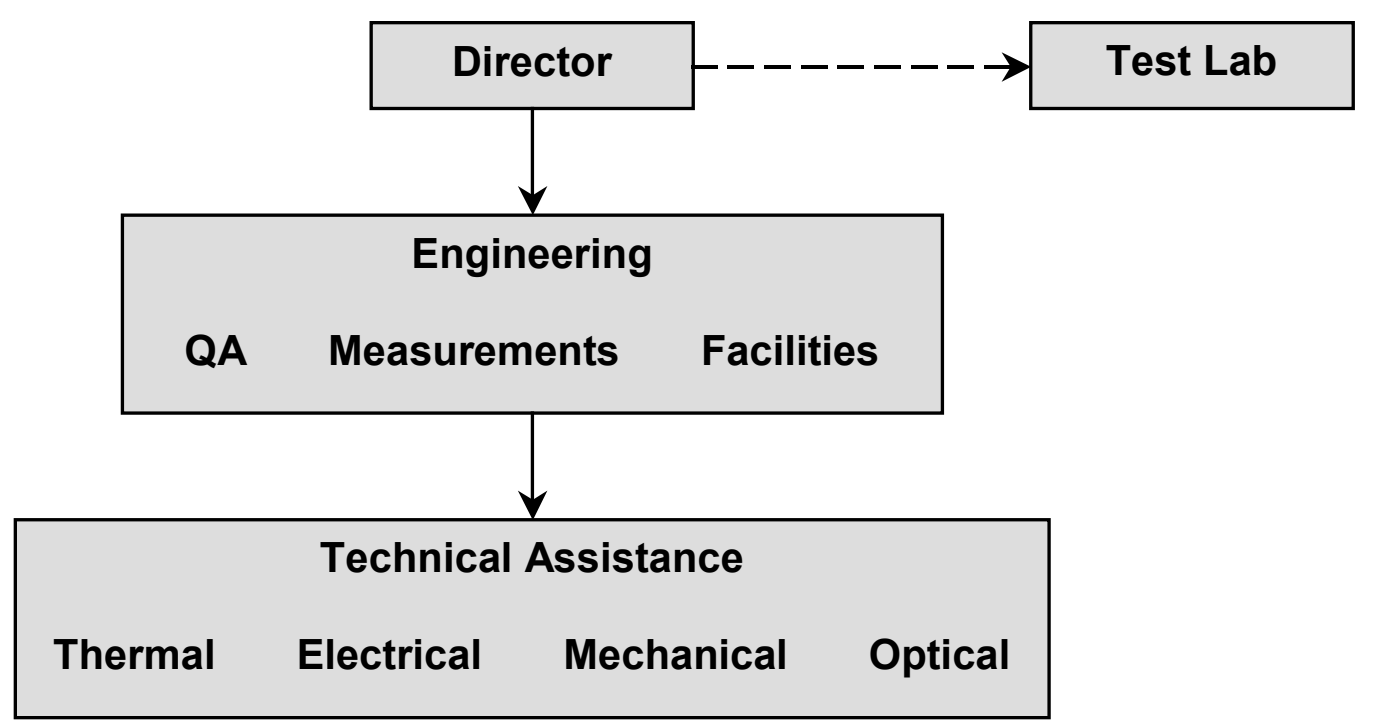

Figure B-2. Laboratory organization

\section{B.8.9 Functional Requirements}

The functions needed to operate the laboratory depicted in Figure B-2 are listed below.

\section{Director}

- Provides technical expertise, marketing, and leadership for the laboratory

- Provides customer interface

- Provides interface to the certification body

- Maintains contacts and information flow with government, industry, and organizations relevant to the laboratory's business

- Is responsible for the overall laboratory operation; sets and maintains laboratory policy

- Reviews all records and reports

- Sets and keeps budgets

- Plans the laboratory needs for personnel and equipment

- Reviews the performance of the laboratory and its personnel

\section{Quality Assurance}

- Conducts and records all calibration functions

- Writes, maintains, and controls the quality manual

- Reviews all reports and periodically checks data

- Conducts training

- Acquires, keeps, and maintains all physical standards and certificates

- Helps select and qualify laboratories for outside testing if such testing is required

- Establishes and maintains relationships with vendors

- Provides interface and communications with engineering

- Conducts annual audit

- Is responsible for plant safety program 


\section{Measurements Engineering}

- Is responsible for all product testing

- Plans flow, logistics, and personnel requirements

- Prepares all technical reports

- Arranges and conducts special tests, i.e., round-robin

- Supervises outside testing and checks results

- Plans for and is responsible for equipment calibration

- Interfaces with quality assurance

- Provides technical training

- Establishes standards and reviews performance of laboratory personnel

- Provides interface and reacts to communications from quality assurance

\section{Equipment/Facilities Engineering}

- Maintains all equipment

- Provides for equipment installation or movement

- Provides periodic preventive and required maintenance

- Provides repair and service

- Keeps traceable records

- Maintains building/facility; heating, ventilation, and air conditioning; and support equipment/supplies and cleans

\section{Laboratory Technician (Electrical, Electronics, Thermal, Mechanical, Optical)}

- Conducts assigned tests

- Monitors equipment and testing function

- Records and maintains data log

- Calibrates assigned equipment

\section{B.8.10 Operational Guidelines}

The number of staff will depend on the level of testing and other business the laboratory may conduct. Operation of the laboratory during the development stage should be characterized by a minimum staff of two or three people, with emphasis on an automated, computerized equipment base. For economy and efficiency, selected tests may be sent to qualified outside laboratories.

To obtain and maintain accreditation, the following guidelines are offered regarding organization, personnel, and laboratory function:

- Maintain lines of responsibility and authority, especially in reporting to and interacting with the certification body.

- Maintain and provide good record keeping, especially on calibration, data log books, and certification and training of personnel.

- Follow and ensure all safety regulations. 
- Provide evidence of training and cross-training of technicians and equipment operators. Require that at least two people be trained for each major test or procedure.

- When subcontracting testing, ensure the qualification and competence of the subcontracting laboratory.

- Keep good records of customer communications, especially complaints and complaint resolutions.

- Keep the quality assurance manual current, and ensure that the stated quality system is in force.

\section{B.8.11 Application-Specific Distributed Resource Test Protocols}

New DR configurations and equipment are coming at a fast pace, but most of the related standards are not yet available to define appropriate tests and expected results. As an alternative, test protocols need to be developed from research activities. These protocols need to address expectations for system performance without dictating levels or limits.

Most DR equipment manufacturers will need to take advantage of mass production economies to produce modular units that can be transported and installed easily. Otherwise, custom installations will price small DR systems out of the energy market. Having multiple identical units will allow some degree of prequalification and type testing. An accredited testing laboratory can certify "type tested" DR technology of this kind. This will guarantee that the equipment meets various performance requirements appropriate to the application. Buyers will receive a certificate from the manufacturer.

These certifications will require test protocols that cover the DR system functions and technologies used. One way to categorize these functions, leading to a structure of dedicated protocols, is shown below:

- Reciprocating engines: converting fuel energy into rotating shaft power (primarily diesel)

- Microturbines: converting fuel energy into rotating shaft power (single or dual fuel)

- Generators: converting shaft power into electric power (AC, synchronous, or asynchronous)

- Electric power conversion: converting DC power (fuel cells, PV) into AC power

- Supercapacitors: short-term and standby energy storage (transient ride-through)

- Fuel cells: direct conversion (high efficiency, low emissions)

- Flywheels: short-term and standby energy storage (transient ride-through)

- Fuel conditioning: processing available fossil fuels as fuel supply to fuel cells. 


\section{B.8.12 Opportunity to Apply Compatibility Test Protocols for Distributed Resources}

With widespread use of electronics in equipment and appliances over several decades, utilities and their customers have dealt with a compatibility challenge between end-use equipment and operating environments. Significant resources and facilities have been applied to investigate, understand, and solve power quality-related compatibility problems at the end-use, lowvoltage equipment level and at the utility transmission, distribution, and service entrance. The purpose of these protocols is to facilitate coordination of the realities of the power system environment with the needs of electronic loads by providing a uniform approach to compatibility.

Over the past 10 years, EPRI research efforts led to a family of compatibility test protocols that have been useful to utilities, manufacturers, and users. Today, many of these past efforts related to load compatibility could be focused on the compatibility issues of distributed power systems. Typically, these protocols address equipment immunity, emissions, and energy performance. The similarities in scope of the load equipment test protocols and the tests needed for DR are significant.

EPRI PEAC has developed more than 25 comprehensive test protocols for system compatibility (SC) between various pieces of electronic equipment and the public power supply. These protocols follow a consistent theme for compatibility, reliability, and safety while addressing application-specific and practical problems.

The approach is based on practices in the area of electromagnetic compatibility engineering. In the area of electromagnetic compatibility, the procedure is to first define the environment for the application, which leads to a set of performance tests to demonstrate that specific equipment is capable of operating in that environment. SC also implies that the equipment will not, by itself, degrade the environment or create undesirable side effects on other systems.

Table B-1 shows the organization and numbering of this family of SC test protocols. Both end-use load equipment and DR are included. The number and title of protocols that have been drafted are underlined. Most of the protocols proposed for DR applications have not yet been drafted.

These performance tests are, by necessity, limited to the major aspects of compatibility and do not propose to replace more comprehensive tests performed by others, such as manufacturers' engineering departments, regulatory compliance agencies, or customer acceptance departments. A unique aspect of the SC protocols is the iteration of test results and design modifications aimed at enhancing compatibility rather than a rigid pass/fail assessment. These protocols have been developed from the perspective of electric utilities in consultation with other interested parties, including equipment manufacturers, end users, and various groups involved in test procedure descriptions. 
Table B-1. A Family of Application-Specific Test Protocols for End-Use Equipment and Distributed Resources

\begin{tabular}{|c|c|c|}
\hline \multicolumn{3}{|c|}{ System Compatibility Test Protocols } \\
\hline Equipment Class & Protocol & Specific Equipment \\
\hline $\begin{array}{l}\text { Storage and } \\
\text { Generation }\end{array}$ & SC-005 & AC Bridging Power Application \\
\hline (SC 000-080) & SC-006 & DC Bridging Power Application \\
\hline Equipment & SC-010 & Ultracapacitor-Based AC Stabilizer \\
\hline Ultracapacitor & $\underline{\mathrm{SC}-020}$ & Single-Phase Photovoltaic Power Conditioner \\
\hline Heat Engines & SC-025 & Three-Phase Photovoltaic Power Conditioner \\
\hline Photovoltaic Cells & $\underline{\mathrm{SC}-030}$ & Fuel Cell System for Residential Energy Application \\
\hline Fuel Cells & SC-035 & Three-Phase Fuel Cell System \\
\hline \multirow[t]{2}{*}{ Wind Turbine } & SC-040 & Single-Phase Inverter-Connected Wind Turbine \\
\hline & SC-045 & Three-Phase Inverter-Connected Wind Turbine \\
\hline \multirow[t]{2}{*}{ Microturbine } & SC-048 & Microturbine for Grid-Connected Application \\
\hline & SC-050 & Microturbine for Standalone-Connected Application \\
\hline Combustion Turbine & SC-055 & Grid-Connected Combustion Turbine \\
\hline \multirow[t]{2}{*}{ IC Engine } & SC-060 & IC Engine for Peak-Saving Applications \\
\hline & SC-065 & IC Engine for Standby Applications \\
\hline \multirow{3}{*}{$\begin{array}{l}\text { Universal Interconnect } \\
\qquad \text { (SC 081-099) }\end{array}$} & SC-070 & Three-Phase Automatic Transfer Switch \\
\hline & SC-074 & Three-Phase Static Transfer Switch \\
\hline & SC-076 & $\begin{array}{l}\text { Paralleling Synchronizing Switchgear } \\
\text { Surge Protective Devices Used in Low -Voltage AC Power }\end{array}$ \\
\hline \multirow{10}{*}{$\begin{array}{l}\text { Power Conditioners } \\
\text { (SC 100-199) }\end{array}$} & $\underline{\mathrm{SC}-110}$ & Systems \\
\hline & $\underline{\text { SC-111 }}$ & $\begin{array}{l}\text { Meter-Base Service Entrance Surge Protective Device } \\
\text { Low-Voltage Surge Protective Devices with Communication }\end{array}$ \\
\hline & $\underline{\text { SC-120 }}$ & Ports \\
\hline & $\underline{\mathrm{SC}-130}$ & $\underline{\text { Single-Phase Ferro-Resonant Transformers }}$ \\
\hline & $\underline{\text { SC-140 }}$ & Single-Phase Uninterruptible Power Supplies \\
\hline & SC-150 & Three-Phase Uninterruptible Power Supplies \\
\hline & SC-160 & Active Power Line Conditioners \\
\hline & $\underline{\mathrm{SC}-170}$ & Power Quality Conditioners \\
\hline & SC-171 & Active Power Line Conditioners \\
\hline & $\underline{\text { SC-172 }}$ & Passive Power Line Conditioners \\
\hline
\end{tabular}


One key concept that has been applied in this development is that application-specific test protocols will not be developed in a vacuum. Two significant factors will influence the pace of development and the basic approach. The first is the wide range of emerging technologies and the need to prioritize the selection of technologies by tracking stages of technology development. The second is the fact that other SC test protocols have shown successful application to a variety of equipment and general acceptance by industry.

\section{B.9 General Organization}

All DR system criteria and test guidelines should be taken into consideration when developing application-specific test protocols. Two basic elements should be considered for such protocols, which will dictate the approach to a specific application-oriented, dedicated test protocol. This subdivision might be an oversimplification because some types of the same equipment might be used for different applications, and a strict dedication to a one application-one protocol policy could lead to redundancy or inconsistency. It is therefore important that the "big picture" be kept in mind, offering an overall perspective but without a rigid framework.

\section{B.10 Format}

Each dedicated test protocol should be structured in a consistent format and contain at least the following information for the specific application:

- General test guidelines, including the test system, available instrumentation and equipment, standard test conditions, and relevant standards and documents

- Requirements for test specimens, manufacturer specifications, expected nameplate data, and identification of devices

- Test methodology, categories of tests, test sequence, and definition of the level of tests, i.e., testing a component or a system

- Description of tests to be conducted including rationale, purpose, detailed procedures and precautions for the individual tests, and the expected results - not pass/fail

- Specific test equipment, circuits, and setups

- Plan for documentation, reporting results, and archiving.

The last item of this list might be the most challenging because of the complexity of the many parameters involved in the evaluation. Unless a deliberate effort is applied at the outset of a test program, there is a high risk of producing such large volumes of data that analysis and retrieval might be difficult. Detailed comparisons with test data from other programs would be extremely difficult. 


\section{B.11 Peer Review for Consensus on Test Protocol}

An essential aspect of effective test protocols is that they be considered living documents rather than frozen mandates. As the protocols are developed, an informal peer review should be the first step toward building consensus. Preferably, this group of peers should be sufficiently removed from direct financial and political interests in the specific test programs being considered. Next, the stakeholders who, as their name implies, have a stake in the matter should be consulted and apprized of the development, and their comments should be given due consideration. As test programs are implemented, the cooperative approach recommended earlier (involving as many stakeholders as possible) will be a powerful tool toward gaining acceptance of new DR technologies.

In contrast with formal standard-like documents, the concept of living documents allows for trial use and improve-as-you-go changes, which are difficult to administer in a context of formal standards. On the other hand, there is the pitfall of chasing "moving targets," which can create confusion and reduce the credibility of the program. It will take careful planning, and avoiding the opposite pitfall of too rigid a structure, to achieve proper balance.

\section{B.12 Applying Protocols for Future Certification of Distributed Resources}

The development of SC test protocols for DR equipment should not be conducted in a vacuum. Several organizations are actively engaged in the development of application or certification standards. One of the objectives of standardization of DR equipment certification is to allow simple application of the equipment without a barrage of required testing in each case. The SC test protocols can be an effective contribution to the development of these other standards and regulations. Conversely, the organization performing the development of the SC protocols should have appropriate awareness of what these emerging standards will involve.

\section{B.13 Pilot Testing to Support Protocol Development}

To enable potential DR end users to make objective and rational evaluations of DR technologies, it is necessary to characterize performance by appropriate and well-documented tests. In other words, appropriate performance characterizations should become accepted criteria and standards for performance. Typically, such acceptance can only come about over time, through hands-on experience, and with some level of consensus of interested parties.

Dispersed generation and storage systems are capable of operating on a broad range of fuels in many applications and offer efficient and flexible on-site alternatives. However, the field experience with many of these DR system configurations is very limited. Complex interactions of distributed power with local equipment and the public power supply are not well known or easily predicted. There is a need for hands-on experience both in controlled laboratory tests and in field demonstrations. Also, there is an opportunity to apply emerging test protocols and test drive draft standards. 
Interconnection standards being developed engage some tough technical issues. It is therefore crucial that these standards-making activities have the best technical support and results of testing and studies. This includes preparation of supporting materials and reports, technical transfer efforts, access to laboratory facilities and personnel, and participation in related standards forums. Testing efforts can foster a partnership involving manufactures, utilities, and users of DG technologies; specialized laboratory facilities; hands-on testing; and demonstrations of DG applications.

Fielded system testing complements the more controlled laboratory testing by providing field measurements and documenting actual compatibility issues in DR installations at host utility sites. Examples of applications that provide this opportunity include:

- A natural gas, industrial fuel cell power system with waste heat used for processing - A remote 2-MW diesel generator in a peak-shaving application

- A 10-kW variable speed wind generator demonstrating grid-tied renewable sources

- A 1-MW low-head hydro unit operated by an independent power producer

- A 75-kW microturbine at a commercial building site.

These field tests provide excellent opportunities to objectively analyze performance and compatibility issues that are germane to DR technologies and utility locations, configurations, and state regulations. Host utilities can analyze the operational history and effects on the power system as well as site-specific performance details. Monitoring data collected at each site can be compared with related laboratory test results. 


\section{Example Cooperative Testing Agreement \\ Product Manufacturer's MEMORANDUM OF UNDERSTANDING}

\section{Project for Characterization of a Distributed Resource Device or System}

This memorandum represents the understanding between the Testing Organizations Inc., hereinafter referred to as Tester and hereinafter referred to as Product Manufacturer.

\section{Definitions of Parties Involved}

Product Manufacturer. A supplier of distributed resources equipment or systems. Where the supplier of equipment to be evaluated is other than the product designer and/or original equipment manufacturer (OEM), the supplier shall identify the OEM as part of the equipment materials package.

Sponsoring Organization. For example an electric utility, end-user, or third party that has provided funding for the project.

Sponsoring Manufacturer. Product manufacturers that have provided funding for evaluating their own product(s) in the project.

\section{Goals}

The broad objective of the project is to establish and define baseline performance capability relative to the product specifications and expectations of product capability as described in the test protocol. Also, the project is expected to provide value to participants as follows:

Value to end-users is achieved from improved understanding of DR equipment performance capability and system compatibility as it applies to end-user systems and to the interface with the electric service source, feedback on operating/instruction manuals, ease of installation and maintenance, drive robustness, environmental compatibility, and troubleshooting/ease of repair.

Value to product manufacturers is realized from (a) receipt of feedback on electric utility system objectives regarding system compatibility, (b) baseline test results that measure current product performance versus expectations, (c) understanding the generic relationship of their product performance capability versus that of other industry suppliers, (d) opportunities to enhance current and future products to better meet customer expectations and system compatibility requirements of the target customer base, and (e) the use of tester test results not as a product endorsement but as a partnership in research with a statement of commitment to meet customer needs.

Value to electric utility sponsors is realized from baseline assessment of DR equipment performance capabilities, resulting information database necessary to support definition of requirements and goals for DR application, and ability to reasonably evaluate expectations versus system capabilities based on a broad base of DR equipment products.

Value to all parties is realized when real-world needs and values are communicated with a common goal of promoting the application of proven technology, technology that supports energy efficiency, improved productivity, and economic growth potential for all parties. 


\section{Scope of Work}

The Sponsors have contracted for independent test results, under controlled conditions and common test practices and procedures, necessary to define and quantify performance and system compatibility of . The work will identify baseline product capability and identify areas in which additional work may be required to meet future sponsored identified objectives.

\section{Application-Specific Test Protocol}

Testing will be conducted by the Tester based on performance criteria developed especially for this project, (protocol identification). A draft copy of this document will be provided to participating Product Manufacturers. Valid comments from the manufacturers and other reviewers will be incorporated into the protocol version, which will be used during the project. This project will not necessarily perform all the tests included in the test protocol, as the project will focus on certain elements to be specified by the Sponsors. The preliminary envisioned scope of the Product Performance Tests is attached to this agreement. In addition, initial test information to be provided as part of the test plan definition will include:

Example initial test info

* HP requirement for each sample

* Efficiency will be measured at each defined load point, as part of the data acquisition process.

* Temperature rise will be measured (with installed thermocouples, RTDs, or simple surfacemounted device) at each load point as part of the test process.

\section{Product Manufacturer's Obligation}

Product Manufacturers that agree to participate in the project will be expected to provide three (3) current technology samples per model selected for evaluation. Final selection of products to be evaluated will be determined by the Sponsors. Products submitted for evaluation must be accompanied by the Product Manufacturer's certification that the samples are randomly selected and representative of the products bearing the same model number that are available to consumers through normal distribution channels. Any deviations from the standard production model should be noted. Complete documentation of each submitted model including specifications, general circuit topology, theory of operation, and a list of standards to which the product has been tested should be provided with the product. Product documentation that should be treated as proprietary information must be so noted and, upon request, will be returned to the Product Manufacturer following completion of the project. Product samples provided by the Product Manufacturer may be retained by Tester for research purposes unless disposition is otherwise directed by the Product Manufacturer.

In summary, the Product Manufacturer would provide basic background information that would support the Sponsor's evaluation of the inclusion of the product in the test program. 
Such information would address:

* Introduction date of product

* Product manufacturing and/or assembly location

* Technology information

* Current and projected unit sales

* Industry and application focus

* Name brand information (as applicable)

\section{Tester Obligation}

Product Manufacturers will be requested to review the pre-setup test conditions that they anticipate will result in best performance for the tests described in the project test protocol. Tester will conduct the tests in accordance with the most recent draft of the test protocol and provide each Product Manufacturer with test results for its specific products. Test data for all products tested will be summarized in a generic report (no manufacturer-specific information) and distributed to all participating manufacturers. A proposed project timetable for accomplishing the scope of the work follows:

\section{Example of milestone dates to be specified:}

* Receipt of Product Manufacturer's summary information completed

* Date for Sponsor decision on Product Manufacturer partnerships

* Signing requirement for MOU

* Product "on site"

* Completed test plan schedule

* Test reports (7 days after each test)

* Reevaluation test period (if applicable)

* Definition of test plan (for information) and subsequent test cost (applicable to manufacturer-contracted testing with Tester)

\section{Product Damage and Reevaluation}

Product Manufacturers are encouraged to pre-set their product for best performance during the proposed tests. The Product Manufacturer's single point of contact for Tester communications shall be designated. Requests for participation during the product testing should be made by the Manufacturer to the Tester-designated technical point of contact by a date prior to when Tester plans to begin testing. The testing is not considered to be a "pass/fail" evaluation of any product. However, if a product sample is damaged during any test, it will be replaced once from the samples provided by the Manufacturer and tested again. As the production of timely test results is dictated, failure of the second sample on the same test will be noted, and the evaluation will continue to the next test. Product failures that would prevent further meaningful testing will be made known to the Product Manufacturer of the failed product. When requested, details of the conditions of failure and return of the failed product, at the Product Manufacturer's expense, will be offered to the Product Manufacturer. 
Following the completion of the Sponsor-funded test evaluation phase, an opportunity to retest units that failed during initial test, or units that have been enhanced to improve system compatibility, will be provided. Reevaluation, or evaluation of enhanced products, will need to be financially supported by the Product Manufacturer. Subsequent testing that will be included in the summary report must be completed within the project-defined time period. Cost details to complete testing, as it is determined based on the final test scope, will be provided to the Product Manufacturer.

\section{Test Results}

All information obtained on specific products during the testing is considered proprietary information and will be disclosed only to sponsoring organizations that have entered into agreements with the Tester to keep the results proprietary. Upon completion of each test, participating Product Manufacturers will receive the information about their own products to assist in evaluating their product's power quality performance and, where appropriate, encourage product improvement. The final test results will not be provided until the first phase of the project is completed. The Product Manufacturer will have 10 business days to comment on the results before the results will be distributed to the Sponsors. Results will be transmitted by express mail or fax.

\section{Use of Test Results}

Product Manufacturers are free to use their test results internally but will only disclose to third parties a specially formatted summary of the results that will also be provided to the Product Manufacturer by EPRI PEAC. Although the test results and procedures will be verified by Tester, the Product Manufacturers are not to state or imply any endorsement of their product by Research Organization, Tester, or any of the Sponsors.

\section{Release From Liability}

The parties recognize that the project includes new and experimental testing and performance by Tester. Tester does not guarantee results. Tester makes NO WARRANTY, EXPRESS OR IMPLIED AND MAKES NO WARRANTY OF MERCHANTABILITY OR OF FITNESS FOR ANY PARTICULAR PURPOSE. 


\section{ATTACHMENT Anticipated Scope of Tests}

\section{Product Performance Tests}

Performance tests will be selected by sponsors from the latest version of the test protocol applicable to this equipment and application. The interest of the participants and budget will determine the final number of tests conducted. Tests will be selected from the list below. Tests denoted with an asterisk $(*)$ are those that are planned under a minimum scope of work:

\section{Baseline Tests}
a. Electrical Characteristics During Start-Up*
b. Steady-State Electrical Characteristics*

\section{Energy Efficiency and Performance Tests}
a. DR Energy Efficiency at Full Load*
b. DR Energy Efficiency at Part Load*

\section{Emission Tests}
a. Line Current Distortion*
b. Output Current and Voltage Distortion*
c. Audible Noise
d. Conducted Emissions (Above $3 \mathrm{kHz}$ )
e. Radiated Emissions (frequencies to be determined)

\section{Immunity Tests}
a. Response to Low Steady-State Input Voltage*
b. Response to High Steady-State Input Voltage*
c. Response to Low Steady-State Harmonic-Distorted Input Voltage
d. Response to High Steady-State Harmonic-Distorted Input Voltage
e. Response to Nominal Steady-State Harmonic-Distorted Input Voltage*
f. Response to Transient Voltage Sags (Ride-Through)*
g. Response to Transient Voltage Swells
h. Response to Transients From Typical Capacitor Switching (5 kHz Ring Wave)*
i. Response to Voltage-Notching*
j. Response to $100 \mathrm{kHz}$ Ring Wave
k. Response to $10 / 1000 \mu \mathrm{s}$ Wave
1. Response to $1.2 / 50 \mu \mathrm{s}-8-20 \mu \mathrm{s}$ Combination Wave*
m. Response to Electrical Fast Transient (EFT) 


\section{Systems-Level Tests}
a. Harmonic Penetration Levels
b. System Frequency Response
c. Response to Capacitor Switching at Different Capacitor Bank Locations
d. Response to Single and Double Line-to-Ground Faults
e. Response to Line-to-Line Faults
f. Optimal Harmonic Filter Location 


\section{Appendix C: Interconnection Agreement Handbook Outline}

(Initial discussion draft for upcoming stakeholder review)

\section{C.1 Abstract}

In two to three paragraphs, the abstract will provide a condensation of what the handbook covers. It will include links to relevant DER documents and programs and marketing and educational programs.

\section{C.2 Acknowledgments}

The acknowledgments will gratefully recognize the guidance provided by key project managers and organizations, those associated with project communications and administration, and committee members.

\section{C.3 Criteria Implementation Committee Members}

A comprehensive list of the criteria implementation committee members and their affiliations will be included in the handbook's front matter.

\section{Section 1}

\section{C.4 Introduction to Interconnection Agreement Handbook}

\section{C.4.1 Purpose}

This purpose of the Distributed Energy Resources Interconnection Agreement Handbook is to provide procedures and guidance, pertinent information, and resources aimed at standardizing and simplifying the interconnection requirements for DER. It includes the requirements of specific states and presents several examples of interconnection agreements. Although the actual requirements may vary by location and jurisdiction, the handbook will attempt to address the important issues that owners of DER will likely confront during the DER interconnection process. The handbook focuses on the electrical interconnection. It identifies additional interconnection requirements but does not comprehensively address them. For example, there may be additional national, regional, state or local requirements related to interconnection (e.g., siting, emissions, building, and safety codes).

\section{C.4.2 Objectives of the Handbook}

This section will discuss why the handbook is needed, the objectives of the handbook, and what role the handbook serves in the overall DER interconnection process.

\section{C.4.3 State Interconnection Requirements}

The handbook will include a review, analysis, and proposed resolution of technical and nontechnical requirements related to interconnection or supporting interconnection agreements being developed by individual states. Significant groundwork has already been laid by various entities toward the development of rules governing the interconnection of onsite DER. This section will provide an overview of the forums that already have been convened by state utility commissions, collaborative groups such as the California Alliance for DER, and others. 


\section{Section 2}

\section{C.5 Terminology}

\section{C.5.1 Introduction}

Terms defined in this section will include acronyms, abbreviations, and symbols used throughout the handbook and that are intended to apply to interconnection agreements, certification, accreditation, and standardization programs in general.

\section{C.5.2 Acronyms, Abbreviations, and Symbols}

\section{C.5.3 Definitions}

\section{Section 3}

\section{C.6 Interconnection Agreement Contents}

\section{C.6.1 Introduction}

The Distributed Energy Resources Interconnection Agreement Handbook will address technical and nontechnical issues to be considered in the development of interconnection agreements. It will outline the "dos and don'ts" of interconnection agreements and provide sample agreements and templates for agreements. Results from selected testing, simulation, and analysis will provide inputs to the agreement process and provide technical data to help resolve disputes.

\section{C.6.2 Interconnection Agreement Terms and Conditions}

This section will explore interconnection agreement terms and conditions with specific rationale, procedures, and requirements to address:

- Identification of the AHJ over interconnection

- Obligations to serve

- Disconnection and reconnection

- Incremental demand charges

- Pre-interconnection studies

- Network interconnection of DER

- Communications concerning proposed DER projects

- Incremental demand charges

- Equipment pre-certification

- Designation of electric service provider contact person(s)

- Time period for processing applications and reporting requirements

- Technical requirements for interconnection and parallel operation on on-site DER system 


\section{Section 4}

\section{C.7 Interconnection Application Process}

\section{C.7.1 Interconnection Application Process}

This section will outline a standard approach for the interconnection application process and include samples of required forms.

1. Interconnection Application

The energy service provider (ESP) and the local AHJ will need to oversee each installation. The ESP and AHJ have very different concerns about the interconnection of the DER system.

2. Determine the AHJ Over the Interconnection

A proposed DER owner will make a formal application to the AHJ for the interconnection of a DER with the ESP system. The application will be made on the appropriate application form provided by the AHJ. (Sample application forms will be included in Annex A.) Often, the AHJ has its own process or defaults much of this process to the local ESP.

3. Determine the ESP Contact Person(s) for Matters Relating to Interconnection of Distributed Energy Resources

The local ESP should designate a point of contact for all matters related to interconnected generation. The ESP point of contact will (list ESP responsibilities).

4. AHJ/ESP Initial Review of Application

Upon receipt of the completed application form and any additional required information, the AHJ/ESP will perform an initial review using the screening process defined in Annex X. The initial review will determine whether the DER (a) qualifies for simplified interconnection, (b) can qualify for interconnection subject to limited additional requirements, or (c) will be required to undergo a pre-interconnection study to determine the interconnection requirement. (The ESP initial review process will be covered in detail in Section 5.)

5. Pre-Interconnection Study

When the initial review reveals that the proposed DER cannot be interconnected by means of a simplified interconnection or with supplemental requirements and that significant additional system components or distribution system improvements may be required, then the ESP and DER owner must enter into an agreement that provides for a pre-interconnection study. A discussion of pre-interconnection study costs that may be imposed by the AHJ/ESP will be included. 
6. Notification to DER Owner of Pre-Interconnection Study Results Upon completion of the pre-interconnection study, the AHJ/ESP will notify the DER owner that the application has been approved or indicate why the application cannot be approved. Such pre-interconnection studies shall not unduly delay the interconnection of the DER.

7. Network Interconnection of DG

Where a DER is to be connected to a network system and capable of exporting power onto the grid, the interconnection study, if needed, may result in more stringent interconnection requirements.

8. Pre-Certification of DER Units, Devices, and Systems When a protective device or system has been pre-certified by the AHJ/ESP or an approved testing laboratory as meeting the requirements of these guidelines, no further review of the unit's design will be required.

9. Connection Approval The DER owner can connect the DER to the ESP system only after the interconnection application has been approved, an interconnection agreement has been executed, and the DER owner has received approval notification. (Additional clarification regarding time limits, etc.)

(Discussion regarding interconnection of residential DER.)

\section{Section 5}

\section{C.8 Authority Having Jurisdiction Review Process}

(This section will discuss details of the AHJ process.)

The AHJ is the organization, office, or individual responsible for approving equipment, an installation, or a procedure. The National Electrical Code (NEC) and 29 Code of Federal Regulations 1910, Subpart S, specify that all electrical installations and equipment are acceptable for use only if approved by an AHJ. Furthermore, the DOE Model Electrical Safety Program recommends that all DOE contractors establish an AHJ for electrical issues such as examining and approving electrical equipment that has not been tested by a nationally recognized testing laboratory.

\section{C.8.1 Purpose}

(This section will discuss the reasons for the initial review process and clearly define the steps required.) 
The purpose of the initial review is to determine:

- If an application qualifies for simplified interconnection without an interconnection study

- If an application may be made to qualify for interconnection with minimal additional requirements

- If an interconnection study is required to determine the requirements for interconnection and to develop a cost estimate and schedule for performing the interconnection study.

Failure to pass any screen does not mean the DER cannot be interconnected. It simply means that further review or studies are required before the DER project will be approved for interconnection with the ESP.

\section{C.8.2 Review Process}

To be added: The review/screening process to determine whether the DER qualifies for simplified interconnection.

\section{Section 6}

\section{C.9 Interconnection Guidelines}

\section{C.9.1 Purpose}

(This section describes typical interconnection requirements, including minimum requirements and procedures for safe and effective connection and operation of DER.)

Provided that the AHJ has approved the DER owner's application to interconnect and the DER equipment meets or exceeds the requirements of these guidelines, a DER owner may operate DER equipment in parallel with the ESP system. Certain specific locations and conditions may require the installation of additional protective hardware, especially when exporting power to the ESP system. If the ESP concludes that an application for parallel operation may require additional protective settings or hardware, the AHJ will make those requirements known to the DER owner as soon as that determination has been made. 


\section{C.9.2 General Interconnection and Protection Requirements}

- Applicable national, state, and local construction and safety codes

- DER protective hardware and software

- Pre-approved equipment

- DER system protection from ESP system inflicted damage

- DER disconnect schemes

- Multiple DER connected to the ESP system through a single PCC

- Applicable circuit breakers or other interrupting devices at the DER owner's facility

- Manual disconnect switch to allow ESP to disconnect DER

- Responsibility for design, procurement, installation, and maintenance of the DER equipment

- Responsibility for any necessary enhancements or improvements needed within the ESP system to accommodate the parallel interconnection of the DER

- Responsibility and liability for the safe and proper operation and control of the DER equipment and the power originating from the DER

- Responsibility to cease parallel operation upon notification by the ESP

- ESP right to specify the type of transformer connection to be used with DER

\section{C.9.3 Preventing DER Interference With ESP System}

- Voltage

- Current

- Frequency

- Flicker

- Harmonics

\section{C.9.4 Control, Protection, and Safety Equipment Requirements}

- Specific small DER $(\leq 25 \mathrm{~kW})$

- DER connected to primary or secondary system $(\leq 50 \mathrm{~kW})$

- Three-phase synchronous generators, induction generators, and inverter systems

- Three-phase connected to primary system $(<1 \mathrm{MW})$

- Generators connected to secondary or primary system (closed transition switching)

\section{C.9.5 Inspection and Start-Up Testing}




\section{C.9.6 Site Testing and Commissioning}

\section{C.9.7 Metering}

\section{C.9.8 References}

\section{Section 7}

\section{C.10 Interconnection Agreement Template}

\section{C.10.1 Introduction}

This section will contain a comprehensive template developed from existing interconnection agreements and inputs from stakeholders. This template can be used as a standard interconnection agreement. Samples of interconnection agreements in use can be found in Annex B.

\section{C.10.2 Interconnection Agreement Template}

\section{Annex A}

\section{C.11 Sample Interconnection Application Forms}

\section{C.11.1 Purpose}

Annex A will outline examples of interconnection applications for different categories of DER systems.

\section{C.11.2 Sample Interconnection Application Forms}

\section{Annex B}

\section{C.12 Sample Interconnection Agreements}

\section{C.12.1 Purpose}

Annex B will contain samples of interconnection agreements for different categories of DER systems based on different technologies, a kilowatt/kilovolt-ampere ratings, and electric service provider control schemes.

\section{C.12.2 Sample Interconnection Agreements}

\section{Annex C}

\section{C.13 References}

\section{C.13.1 Introduction}

The latest industry standards, DER system applications resources, and authoritative articles will be appropriately included. 


\section{Appendix D: EPRI PEAC Corp. Scope of Work}

\section{D.1 Introduction}

This subcontract will address the institutional issues activities in the DOE-DER integration program and consists of a base period with two option periods: Option Period I, and Option Period II. Each option period will be incrementally funded. EPRI PEAC shall complete the investigations described in the following tasks and provide a detailed summary of this work in its reports and deliverables.

In this subcontract, EPRI PEAC Corp. shall design and develop a certification and lab accreditation pilot effort that will be applicable to a broad base and spectrum of the DER equipment and user communities. The pilot certification process shall be demonstrated, and an implementation plan for DER certification and accreditation shall be drafted. EPRI PEAC shall establish criteria and develop an interconnection agreement handbook along with support training, testing, information resources, and hotline services in the marketplace.

\section{D.1.1 Infrastructure for Certification and Accreditation}

The results of this subcontract shall be an industrywide certification and laboratory accreditation model program that can evolve and be implemented. EPRI PEAC will do this by first organizing the stakeholders and then developing a plan to conduct certifications and accredit a nationwide network to provide testing and services. Next, EPRI PEAC will enlist several DER manufacturers and host utilities to participate in a pilot testing and certification process. Finally, EPRI PEAC will refine the process and documents for use at other laboratory facilities, for training, and for developing the hands-on skills of training service personnel, laboratory engineers, field engineers, and other professional service participants.

Specific tasks will include establishing stakeholder roles and responsibilities, rules of engagement, and structure and procedures that lead to the creation of a pilot third-party testing activity. The approach will promote industrywide acceptance by creating a governing board, soliciting inputs on testing and reporting procedures from stakeholders, and designing a standard test protocol template that describes rationale and expected results. Also, supporting tasks will provide tools such as problem-solving forums, Web-based training, organizational workshops, and communications mechanisms.

\section{D.1.2 Handbook and Services Supporting Interconnection Agreements}

The subcontract work shall be a review, analysis, and proposed resolution of technical and nontechnical requirements being developed by the states for interconnection; a distributed electric power interconnection agreement handbook; and other services supporting interconnection agreements. Evaluations shall apply results from testing and any required simulation and analysis to provide sound inputs to the agreement process or to resolve disputes. The handbook shall address technical and nontechnical issues to be considered in the development of interconnection agreements, the "dos and don'ts," and templates for interconnection agreements.

EPRI PEAC's tasks are described in the following subsections for each period. 


\section{D.2 Base Period: Tasks 1-2}

EPRI PEAC shall report all progress from this base period task-oriented research through reporting requirements detailed below. EPRI PEAC shall report the progress of the tasks in the appropriate monthly or quarterly deliverable reports and then in the annual report.

\section{D.2.1 Task 1: Requirements for Third-Party DER Equipment Certification}

This task is intended to finish the preliminary work to secure industry, DER, and utility buy-in for a pilot certification effort. The subtask activities include engaging appropriate stakeholders, developing a road map, and developing criteria for pilot laboratory certification of DG interconnections. The result shall be the establishment of criteria and requirements and a development plan for the structure and function of DER product certification and laboratory accreditation.

\section{D.2.1.1 Subtask 1.1: Organize Stakeholders and Develop Roadmap for Certification and Accreditation}

This subtask shall focus on identifying and organizing the team of DER stakeholders for their participation and constructive feedback on subsequent subtasks. In Subtask 1.1, EPRI PEAC shall identify and organize stakeholders to develop a proposed road map to a certification and accreditation plan and assist with the future development of the final draft interim plan for certification and accreditation activities.

The DER stakeholders shall be identified and solicited for their participation in the establishment of the criteria, requirements, and plan for DER certification and accreditation. The certification road map shall build on, and include, meaningful, relevant, and existing certification programs, including those from industry and from a national and international perspective, as a basis. The perceived "strengths and weaknesses" of these existing programs shall be examined to identify latent certification and accreditation problems and proposed solutions for moving forward.

\section{D.2.1.2 Subtask 1.2: Draft Certification and Labeling Criteria for Interconnection} EPRI PEAC shall examine the implications of current practices, planning, methodologies, power system training, policies, regulations, ownership structures, and other issues on DER applications. From this base of material, EPRI PEAC shall develop and implement a systematic process that establishes criteria and requirements for developing equipment test protocols and documenting certifying procedures. The criteria and requirements shall include elements addressing the level of knowledge required of professional services businesses and others who work with DER equipment and interconnection activities. The draft criteria and requirements will serve as the vehicle to develop constructive feedback from all DER players in "bounding" proper DER equipment performance envelopes and electric supply interconnection issues. EPRI PEAC will distribute and solicit industrywide feedback on the draft criteria. Using the feedback, EPRI PEAC will create a certification and accreditation plan for a model program for DER technologies and their applications. 
The primary focus shall be to establish criteria and requirements to create uniform interconnection standards for DER technologies by embodying a "labeling" methodology as a common benchmark for moves toward standardization. In addition to safety and reliability elements, the criteria and requirements will assist DER players with equipment choices and installation configurations for enhancing the understanding of opportunities for hybrid systems. Although the criteria and requirements may need to differ in some respects to account for unique DER technology characteristics or for effects of differently rated equipment, the criteria and requirements shall be written to support flexible and cost-effective DER resources leading to uniform standards.

\section{D.2.1.3 Subtask 1.3: Design and Develop Beta Site for Web-Based Certification Information}

To further encourage the coordinated deployment of DER systems, EPRI PEAC will develop a beta Web site containing Web-based information resources that will provide status and plans for development of the DER certification process. The beta site will contain up-to-date information on certification requirements and will eventually be used to support the interconnection handbook, typical agreements, and accreditation procedures developed in future tasks. It is envisioned that the site can provide interconnection and certification information for specific DER technologies and will include links to major DER manufacturers and distributors, DER standards activities, state regulatory agencies, etc.

\section{D.2.2 Task 2: Assessment of Interconnection Agreement}

The work consists of two main subtasks, which are described below.

\section{D.2.2.1 Subtask 2.1: Research and Report on Emerging Interconnection Agreements} EPRI PEAC shall review and analyze the forums that have already been convened by state utility commissions (e.g., New York and Texas), European industry groups such as the IEEE, collaborative groups such as the California Alliance for Distributed Energy Resources, and others. Significant groundwork has already been laid by these parties in substantive rules governing the interconnection of on-site DG.

\section{D.2.2.2 Subtask 2.2: Develop Rationale and Contents for Handbook Supporting Interconnection Agreements}

EPRI PEAC shall research existing documents and procedures and develop a rationale, outline, and required contents for an interim interconnection handbook based on the above task results. At a minimum, the interim handbook shall explore terms and conditions; obligations to serve, disconnection, and reconnection; incremental demand charges; preinterconnection studies; network interconnection of DER; communications concerning proposed DER projects; equipment pre-certification; designation of utility contact persons; time periods for processing applications and reporting requirements; and the technical requirements for interconnection and parallel operation of on-site DER systems. Also, a preinstallation assessment procedure, an industry standard approach for resolving disputes, and an annotated bibliography shall be included. 


\section{D.3 Option Period I: Tasks 3-5}

EPRI-PEAC shall report all progress from this option period task-oriented research through reporting requirements detailed below. EPRI-PEAC shall report the progress of the tasks in the appropriate monthly or quarterly deliverable reports and then in the annual report.

\section{D.3.1 Task 3: Pilot for Third-Party DER Equipment Certification}

Equipment testing and test protocol initiation are interdependent. Industry-accepted test protocols are necessary for conducting meaningful and repeatable testing. Important lessons learned from ongoing testing experiences must be incorporated into the test protocols to ensure they remain current. Therefore, pilot certification testing and the drafting of a formal test protocol are done in parallel.

\section{D.3.1.1 Subtask 3.1: Lab Testing for Certification of Sample DER}

EPRI PEAC shall conduct testing on the first selected DER technology. The following shall be addressed as a minimum:

- Develop the initial DER technology labeling criteria and requirements to guide the development of certification testing procedures and final development of the certification/accreditation plan.

- Use existing test protocols on similar equipment to define technical details, rationale, and expected results from each test; provide beta labels and certification beta reports.

- Identify manufacturers of the selected technology to be beta tested, and solicit manufacturer participation in the testing.

- Develop and sign testing agreements with equipment manufacturers that offer DER units for test.

- Obtain the DER units to be tested from participating manufacturers.

- Work with participating DER manufacturers to refine the beta test plan.

- Conduct beta testing.

- Work closely with manufacturers and steering group to resolve any issues during beta testing.

- Verify critical operating parameters for each DER system tested. These parameters will allow software developers to develop accurate and reliable models of common distributed generators for use in commercial software tools.

- Analyze the overall certification and labeling process, and recommend improvements, needs, approaches, and rationale. 


\section{D.3.1.2 Subtask 3.2: Drafting of Application-Specific Test Protocols}

Test protocols need to be developed as part of the certification program. Using existing test plans and standards, information from the certification pilot testing, stakeholder feedback, and knowledge from years of equipment characterization and test protocol development, EPRI PEAC shall initiate the first drafts of one DER certification test protocol. These test protocol documents are necessarily "living documents," which are maintained and become more refined with each new testing experience. The process begins with a basic test plan that addresses the concerns without specific test specification. Using the test plan for testing helps refine the procedure and often raises new issues and provides new observations that must be added to the procedure. After the testing, the test plan is enhanced with the addition of lessons learned and becomes the basis for the draft test protocol document that will ultimately become a formal test protocol document. This, in turn, will be used for all subsequent certification testing of application-specific DER equipment.

\section{D.3.1.3 Subtask 3.3:Continued Development and Maintenance of Certification Information Resource Beta Site}

Information modules will be added from the base period work. A module on interconnection agreements and one on the interconnection handbook will be added. Also, the site will be updated with the latest technical and regulatory activity in the area of DG. These activities are extremely dynamic and are expected to be dynamic for the next several years. It is worthwhile that the latest information be readily available. EPRI PEAC will keep abreast of activities related to DER certification and continue to maintain and enhance the Web-based DER certification resource established in the base period.

\section{D.3.2 Task 4: Certification and Laboratory Accreditation Plan}

From the experience of the pilot testing and feedback, EPRI PEAC shall establish a draft certification and laboratory accreditation plan that shall be reviewed by stakeholders (e.g., a national distributed power coordinating committee) and national accredited testing laboratories for guaranteeing that the equipment meets standard interconnection requirements approved by state regulators. The plan shall emphasize how buyers of DER equipment will receive a "grid compatible" certificate from DER manufacturers that will greatly simplify the grid connection process. Under the plan, state regulatory authorities would require utilities under their jurisdiction to accept the "grid compatible" certificate in lieu of costly engineering studies. The plan shall extend beyond the criteria established in the first period activities. The plan will be along the lines of an implementation handbook (i.e., to include a proposed implementation process as well as drafts of proposed documents necessary for implementation, e.g., quality system for laboratories, instrumentation calibration, traceability and statistical measurement requirements, model for certification and labeling, testing requirements, organizational documents, bylaws, rules of procedure, and outreach/educational program documents).

\section{D.3.3 Task 5:Final Draft Handbook Supporting Interconnection Agreements}

The concurrent results and considerations of all the above subtasks and tasks shall be used to establish the final draft handbook. As a minimum, the final draft handbook shall explore terms and conditions; obligations to serve, disconnection, and reconnection; incremental demand charges; pre-interconnection studies; network interconnection of DER; 
communications concerning proposed DER projects; equipment pre-certification; designation of utility contact persons; time periods for processing applications and reporting requirements; and the technical requirements for interconnection and parallel operation of on-site DER systems. Also, a pre-installation assessment procedure and an industry standard approach for resolving disputes shall be included.

\section{D.4 Option Period II: Tasks 6-8}

EPRI PEAC shall report all progress from this option period task-oriented research through reporting requirements detailed below. EPRI PEAC shall report the progress of the tasks in the appropriate monthly or quarterly deliverable reports and then in the annual report.

\section{D.4.1 Task 6: Ongoing Pilot for Certification Testing and Test Protocol Development}

Ongoing equipment testing and test protocol development for different types of DER technology are necessary to establish a viable certification program. This task is a continuation of that initial pilot certification testing and serves to further refine the certification process prior to initial accreditation of other laboratories.

\section{D.4.1.1 Subtask 6.1: Lab Testing for Certification of Example DER}

EPRI PEAC shall conduct certification testing on the next selected DER technology. This task shall consider the existing criteria and requirements and all pertinent results from the tasks and subtasks in this subcontract. For example, the following shall be addressed as a minimum:

- Use DER technology labeling criteria and requirements results to guide development of certification testing procedures and refinements of the certification/accreditation plan.

- Employ available test protocols and standards to define technical details, rationale, and expected results from each test; provide certification labels and certification reports for the selected DER technology.

- Identify and solicit DER manufacturer participation in certification testing.

- Develop and sign testing agreements with the equipment manufacturers offering DER units for test.

- Obtain DER units for testing from participating equipment manufacturers.

- Work with participating DER manufacturers to refine the certification test plan.

- Conduct certification testing on the selected DER technology.

- Work closely with manufacturers and steering group to resolve any issues during certification testing.

- Determine DER operating parameters for use in developing accurate and reliable models for computer simulation of common DER systems.

- Analyze the overall certification and labeling process and recommend improvements, needs, approaches, and rationale. 


\section{D.4.1.2 Subtask 6.2: Drafting of Application-Specific Test Protocols}

Additional test protocols will need to be drafted as part of the ongoing certification program. Using existing test plans, standards, the certification pilot testing, stakeholder feedback, and lessons learned from years of experience in equipment characterization and test protocol development, EPRI PEAC shall initiate the first draft of a DER certification test protocol for the selected DER technology tested.

\section{D.4.2 Task 7: Support Tools for Creating Interconnection Agreements}

To support simplified and standardized interconnection agreements, a coordinated information dissemination, education, and training effort is necessary to ensure that all parties have access to the information they need to make informed decisions relative to interconnection. There will be a growing demand for interactive, Web-based tools and training and for communications mechanisms such as organizational workshops, problemsolving forums, and perhaps even an information hotline where accurate information can be compiled and easily obtained by a simple phone call or e-mail message.

Computer modeling of modern DER systems is unreliable because software developers do not have information about DER system parameters needed to develop reliable computer models. Models will need to be verified by comparison with actual DER systems tested in the laboratory. This will become even more important for the DER systems that are to be certified grid compatible.

\section{D.4.2.1 Subtask 7.1: Continued Development and Maintenance of Certification Information Resource Beta Site}

Information modules will be added from the Option Period 1 work. A new module on certification procedures and protocols will be created. Also, a module on accreditation procedures will be added, and the final handbook on agreements will be described and available. All materials will be Web-based with the usual point-and-click, indexing, and search features.

\section{D.4.2.2 Subtask 7.2: Develop an Interactive, Web-Based Interconnection Agreement Handbook}

To encourage the systematic and coordinated introduction of grid-connected DG systems, there is a need to simplify the interconnection process by making the interconnection handbook widely available in a user-friendly, Web-based interactive tool. This can be accomplished by converting the final draft handbook into an interactive, Web-based tool that can be easily updated with current information. At a minimum the handbook will contain information about terms and conditions; obligations to serve, disconnection, and reconnection; incremental demand charges; pre-interconnection studies; network interconnection of DER; communications concerning proposed DER projects; equipment precertification; designation of utility contact persons; time periods for processing applications and reporting requirements; the technical requirements for interconnection and parallel operation of on-site DER systems including any additional or special requirements for specific installation locations; a pre-installation assessment procedure; an industry standard approach for resolving disputes; and available grid-certified DER equipment. It will also 
provide up-to-date information about certification and accreditation, grid connection requirements, operational constraints, etc.

\section{D.4.2.3 Subtask 7.3: Develop Web-Based Interconnection Training}

EPRI PEAC shall develop Web-based technical training courses covering the selection, installation, operation, and grid connection of DER equipment. Equipment certification and interconnection requirements shall be covered, and there will be an overview of the various DER technologies and typical applications of each type of technology. Information about manufacturers, including links to vendors with grid-certified equipment, will be included.

\section{D.4.3 Task 8: Screen and Identify the Laboratories for Accreditation}

Based on the requirements of the final draft certification and accreditation plan, EPRI PEAC will work with NREL to identify candidate laboratories for accreditation. Candidates will be surveyed to determine interest and motivation for accreditation. The candidate laboratories will be documented by the end of Option Period II. 


\section{Appendix E: Resources}

\section{E.1 History of Interconnection Standards}

The Public Utilities Regulatory Policy Act of 1978 enabled independent generators to sell electricity to regulated utilities. In the mid-1980s, with significant support from an industry fueled by DOE renewable energy programs and the Public Utilities Regulatory Policy Act, IEEE sponsored the development of the first DR interconnection standards. Several documents were published, including IEEE Standard 929, ANSI/IEEE 1001-1998, ANSI/IEEE 1021-1988, and ANSI/IEEE 1035-1989 from IEEE SCC23 on Dispersed Storage and Generation. SCC23 was primarily made up of power engineers with utility system relaying and protection experience and included several recognized experts and fellows of IEEE. The following paragraphs provide a brief overview and history of these early interconnection standards.

\section{E.1.1 IEEE 929 - 2000 Recommended Practice for Utility Interface of Photovoltaic Systems}

In January 2000, the IEEE Standards Board approved a revised standard for interconnecting PV systems less than $10 \mathrm{~kW}$ with the utility grid. This recommended practice supercedes IEEE 929 - 1988 (R1991). It describes the interface, functions, and requirements necessary in the interconnection of a PV power system with an electric utility. It addresses issues of power quality and equipment protection and describes the acceptable and safe practices for accomplishing those functions and meeting the requirements. This recommended practice applies to utility-interconnected PV power systems, primarily single-phase and less than 10 $\mathrm{kW}$, operating in parallel with the utility grid and using static (solid-state) inverters. It does not apply to systems using rotating inverters. Tests include harmonic distortion, voltage flicker, grounding, DC injection, utility voltage and frequency variations, and anti-islanding.

\section{E.1.2 ANSI/IEEE 1001 - 1988 Guide for Interfacing Dispersed Storage and Generation Facilities With Electric Utility Systems}

This standard included a comprehensive overview of nonutility dispersed generation, including a rundown of utility engineering issues and recommended relaying protection schemes for interconnection. It expired in December 1995 when it was not reaffirmed within the IEEE 5-year time limit.

\section{E.1.3 ANSI/IEEE 1021 - 1988 Recommended Practice for Utility Interconnection of Small Wind Energy Conversion Systems}

This recommended practice provided the necessary guidelines and operating procedures to connect and operate a small wind energy conversion system, with interface, in parallel with an electric utility system. Installation approval procedures were covered as were issues related to the utility interface, equipment protection, power quality, and safety of operating personnel and the general public. The standard was withdrawn in May 1996. 


\title{
E.1.4 ANSI/IEEE 1035 - 1989, IEEE Recommended Practice: Test Procedure for Utility-Interconnected Static Power Converters
}

This recommended practice was a test procedure for single- and three-phase static power converters rated from $1 \mathrm{~kW}$ to $500 \mathrm{~kW}$, but it could also be applied in principle to larger units. It covered the less well-known inverter interface and encouraged more "on board" control and protection functions. The concept of the built-in interface was to avoid relatively high-cost utility-grade relay packages for small, dispersed generators involving DC technologies that needed an inverter for connection to the utility grid. The objective was the measurement of electrical parameters at the $\mathrm{AC}$ terminals of the power converter. The procedure could also serve as a basis for factory or acceptance testing. The test results could be used for evaluating or comparing different types of static power converters. Only equipment with the primary function of delivering electric energy to circuits interconnected with the electric utility was covered by this procedure. This recommended practice was withdrawn in May 1995 when it was not reaffirmed within the IEEE 5-year review cycle.

\section{E.1.5 Interconnection Standards Today}

These early interconnection standards and many of the people involved in their origination provide the catalyst today for a new IEEE initiative on interconnection standards. In March 1999, the IEEE Standards Board voted to undertake the development of uniform standards for interconnecting DR with EPSs. The recently approved interconnection standard, IEEE 1547 2003, and the developing IEEE 1547 series are discussed in Section 3 of this report. The latest information on IEEE 1547 and the 1547 series is available at http://www.eere.energy.gov/distributedpower/interconnection_ieee.html. The IEEE 1547 and IEEE 1547 series efforts are sponsored by IEEE SCC21.

\section{E.2 Federal Distributed Energy Resources Interconnection Rules and Agreements}

\section{Federal Energy Regulatory Commission}

18 Code of Federal Regulations Part 35 - Generator Interconnection Activities

http://www.ferc.gov/industries/electric/indus-act/gi.asp

\author{
National Association of Regulatory Utility Commissioners \\ Model DER Interconnection Procedures and Agreement \\ http://www.naruc.org/programs/dgia/dgiaip.pdf
}

Model Distributed Generation Interconnection Procedures and Agreement

http://www.naruc.org/programs/dgia/dgiaip.pdf

\author{
National Regulatory Research Institute/National Association of Regulatory Utility \\ Commissioners \\ Distributed Generation Interconnection Policy Issues \\ http://www.nrri.ohio-state.edu/programs/electric/DistributedGeneration/
}




\section{National Rural Electric Cooperative Association}

Business and Contract Guide for Distributed Generation Interconnection http://www.in.gov/iurc/utilities/energy/distribute/statewide att1.doc

\section{E.3 State Interconnection Rules and Agreements}

Over the past few years, several states - California, Texas, New York, and Ohio - have completed DER interconnection procedures and agreements for small generators after extensive stakeholder processes. Other states have also begun to consider how to implement DER. The following are brief overviews of the interconnection requirements and typical interconnection documentation requirements of California, New York, Ohio, and Texas. These are followed by links to interconnection activities in many other states.

\section{E.3.1 California}

California was one of the first states to adopt a standard practice for the interconnection of DER devices with the electric grid. In October 1999, the California Public Utilities Commission issued an order instituting a new DER rulemaking (99-10-025) to address interconnection standards. This rulemaking progressed into the rewriting of Rule 21, part of each investor-owned utility's tariff, by a working committee that included representatives from the California Energy Commission and the state's electric utilities. The new version of Rule 21 specifies standard interconnection, operating, and metering requirements for DER generators.

On Dec. 21, 2000, a California Public Utilities Commission decision (00-12-037) approved in its entirety the Rule 21 language adopted by the California Energy Commission. Pacific Gas and Electric Co., San Diego Gas and Electric Co., and Southern California Edison Co. have now replaced their former Rule 21 with the approved Model Tariff, Interconnection Application Form, and Interconnection Agreement. Specific information regarding the interconnection of DER technologies is available from each of the utilities.

Pacific Gas and Electric Co.

Rule 21 - Generating Facility Interconnections http://www.pge.com/customer services/business/tariffs/pdf/ER21.pdf

San Diego Gas and Electric Co.

Rule 21 - Interconnection Standards for Non-Utility-Owned Generation http://www.sdge.com/tm2/pdf/ERULE21.pdf

\section{Southern California Edison}

Rule 21 - Generating Facility Interconnections

http://www.sce.com/NR/sc3/tm2/pdf/Rule21.pdf 


\section{E.3.2 New York}

New York has many DER standards and orders executing connections to utilities. PV less than $15 \mathrm{~kW}$ have a public service commission order with net metering provisions. The standard agreement covers all DG $300 \mathrm{~kW}$ and less (aggregated on the customer side of the PCC connected in parallel to radial distribution feeders. Standard interconnection requirements exist for PV and DER. These are December 1999 public service commission orders and standards requirements. Final interconnection rules and standards are currently under revision from the November 2000 version. DER applications are for $15 \mathrm{~kW}$ or less and $300 \mathrm{~kW}$ or less - a two-tier DER system. The standard requirements can be found at http://www.dps.state.ny.us/SIR Require 03 03.PDF.

\section{E.3.3 Ohio}

As part of the state's 1999 electric utility restructuring law, Ohio established net metering for renewable energy systems, including fuel cells. (Microturbines may also be net metered if they are $100 \mathrm{~kW}$ or less.) Subsequently, the Ohio Public Utilities Commission initiated a lengthy process to establish interconnection rules and procedures. The technical rules cover all DER up to $300 \mathrm{kVA}$; separate provisions apply to small systems up to $25 \mathrm{~kW}$. These are accompanied by a screening document similar to California's, which is a flow chart for the DER interconnection process. The PUC has also a developed sample application, but to apply for interconnection, system owners must use utility applications. Although the Ohio DER interconnection rules do not reference IEEE 1547 or IEEE 929, the requirements essentially mirror these national standards. For small systems, utilities may require an external disconnect.

Procedurally, the screening process establishes the criteria for systems that qualify for a simplified interconnection agreement. A supplemental review is required if the system is larger than the $300-\mathrm{kW}$, three-phase or $25-\mathrm{kW}$, single-phase size limits or if the equipment has not been type tested. Site commissioning tests may still be required in any event to ensure that the system is connected properly and that the protective functions are working properly. Beyond the supplemental review, some systems will require a system impact and facility study in which certain distribution feeder capacity limits are met. Utilities may collect fees to cover the costs of the application process and a refundable deposit if any studies are required to analyze the effect of the customer's equipment on the distribution wires system.

\section{E.3.4 Texas}

The Public Utility Commission of Texas has prepared a manual to guide the inclusion of DG into the Texas electric system. It is intended for use by utility engineers processing DG interconnection and persons considering or proposing the interconnection of DG with a transmission and distribution utility. The procedures are intended to cover most important issues or problems, including a process for prompt dispute resolution. Key sections of the manual cover safety requirements, technical requirements, transmission and distribution utility analyses of DER interconnections, DER applicant information, energy efficiency and customer-owned resources, the pre-certification process, interconnection disputes, definitions, Public Utility Commission of Texas rules, forms, PURA 99 excerpts, summaries of DER technologies, Texas utility contacts, Internet links for electric distribution companies in Texas, additional safety and performance references, and pre-certification requirements. 
The manual is available to the public at http://www.puc.state.tx.us/electric/projects/21965/dgmanual.pdf.

\section{E.3.5 Other State Interconnection Agreements}

The following is a sampling of the emerging rules and interconnection agreements of states.

\section{Arizona}

Draft Interconnection Requirements For Distributed Generation

http://www.dsireusa.org/library/docs/additionaldocs/AZDraftInterconRules1199.pdf

\section{California Energy Commission}

DER Electrical Interconnection Guidebook

http://www.energy.ca.gov/distgen/interconnection/interconnection.html

DOE Office of Distributed Energy Resources

State Interconnection Procedures and Agreements

http://www.eere.energy.gov/distributedpower/interconnection_state.html

Massachusetts Distributed Generation Interconnection Collaborative

Proposed Uniform Standards for Interconnecting Distributed Generation http://dg.raabassociates.org/Articles/Tariff Rev3 5.15.doc

\section{Minnesota}

Distributed Generation Resources

http://www.me3.org/issues/dg/

\section{National Regulatory Research Institute}

Survey of State Interconnection Activities (Includes 26 States)

http://www.nrri.ohio-state.edu/programs/electric/DistributedGeneration/data/national/DERannotation.html.

New York State Public Utilities Commission

Standardized Interconnection Requirements

http://www.dps.state.ny.us/distgen.htm

\section{Ohio Public Utility Commission}

Distributed Generation: How To Get Interconnected to Your Local Electric Utility Company's System http://www.puc.state.oh.us/PUCO/Consumer/information.cfm?doc id=115

\section{Wisconsin Public Service Commission}

Rules and Procedures for Interconnecting Customer-Owned Distribution Generators to Electric Distribution Systems

http://psc.wi.gov/pdffiles/ord notc/5569.pdf 


\section{E.4 Utility Rules and Interconnection Agreements}

The following are examples of interconnection rules and agreements at the utility level.

\section{Hawaiian Utilities}

Interconnection Standards and Interconnection Agreement for Distributed Generating Facilities Operating in Parallel With the Electric Systems of Hawaiian Electric Company, Maui Electric Company, and Hawaii Electric Light Company

http://www.hawaii.gov/dbedt/ert/interconnection/interconnection.html

\section{Idaho Power}

Requirements for Generation Interconnection http://www.idahopower.com/pdfs/aboutus/business/transtariffs/gen_interconnection_requirem ents.pdf

\section{ONCOR}

Distributed Generation

http://www.oncorgroup.com/electricity/distgen/default.asp

\section{Long Island Power Authority}

Interconnection and Regulatory Filings

http://www.lipower.org/papers/inter.html

\section{Los Angeles Department of Water and Power}

Distributed Generation Interconnection

http://www.ladwp.com/ladwp/cms/ladwp001403.jsp

\section{Pacific Gas and Electric}

Distributed Generation Interconnection Requirements

http://www.pge.com/002 biz_svc/gen/retail_gen.shtml

\section{Public Service New Mexico}

http://www.pnm.com/customers/ic_dist_gen.htm

\section{Xcel Energy}

Interconnection Guidelines For Parallel Operation of Distribution Connected Customer-

Owned Generation

http://www4.xcelenergy.com/EnergyMarkets/CustInterconnectGuide/TOC.asp

\section{E.5 Interconnection Rules and Agreements of Other Organizations}

The following are examples of other organizations with interconnection rules and agreements.

\section{Interstate Renewable Energy Council}

Connecting to the Grid

http://www.irecusa.org/connect/index.html 


\section{National Energy Marketers Association}

National Guidelines for Implementing Distributed Generation and Related Services

http://www.state.ma.us/dpu/electric/02-38/726nemadgf.pdf

\section{National Rural Electric Cooperative Association}

Application Guide for Distributed Generation Interconnection: 2003 Update

The National Rural Electric Cooperative Association Guide to IEEE 1547

http://www.nreca.org/nreca/Policy/Regulatory/dgtoolkit/DGApplicationGuide-Final.pdf

New Rules Project

Distributed Generation Interconnection Procedures - Interconnection Standards for

Distributed Power

http://www.newrules.org/electricity/interconnect.html

\section{Western Interstate Energy Board}

Distributed Generation

http://www.westgov.org/wieb/electric/distgen/ - Interconnection

Wisconsin Distributed Resources Collaborative

http://www.wisconsindr.org/links.html

\section{E.6 Distributed Energy Resources Interconnection Tools}

Interconnection and Systems Integration

http://www.eere.energy.gov/der/interconnection

DER Interconnection Library

http://www.eere.energy.gov/distributedpower/library.html

National Rural Electric Cooperative Association

Distributed Generation Interconnection Tool Kit

http://www.nreca.org/nreca/Policy/Regulatory/dgtoolkit/index.html

\section{E.7 Distributed Energy Resources Test Facilities}

National Renewable Energy Laboratory

Fact sheet

http://www.nrel.gov/docs/fy03osti/33403.pdf

Flash presentation

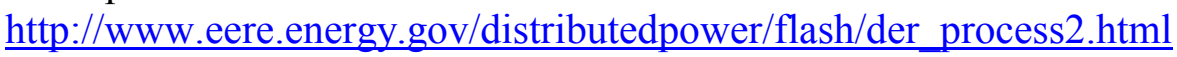

EPRI PEAC Corp.

http://www.epri-peac.com/dg/dg_home.html 
Sandia National Laboratories

Review of Test Facilities for DER

http://certs.lbl.gov/pdf/TestFacilitiesDER.pdf

Underwriters Laboratories

http://www.ul.com/dge/

\section{E.8 Other Useful Links}

Arthur D. Little

White paper: Reliability and Distributed Generation

http://www.encorp.com/dwnld/pdf/whitepaper/wp_ADL_4.pdf

Database of State Incentives for Renewable Energy

http://www.dsireusa.org/

Distributed Power Coalition of America

http://www.distributed-generation.com/dpca/

Department of Energy

DOE Office of Energy Efficiency and Renewable Energy Distributed Energy and Electric Reliability Program http://www.eere.energy.gov/deer.html

DER Energy Management and Grid Support Applications Research http://www.eere.energy.gov/distributedpower/research/emgsa.html

DER Interconnection and Control Technology Research

http://www.eere.energy.gov/distributedpower/research/ict.html

DER Interconnection Research Reports

http://www.eere.energy.gov/distributedpower/reports.html

DER Interconnection Standards and Testing Research

http://www.eere.energy.gov/distributedpower/research/ist.html

http://www.eere.energy.gov/distributedpower/research/ieee p1547.html

DER Regulatory and Institutional Issues Research

http://www.eere.energy.gov/distributedpower/research/rii.html

Distributed Energy and Electric Reliability Program

http://www.eere.energy.gov/deer.html

Distributed Power Program

http://www.eere.energy.gov/distributedpower/links.html 
Introduction to Distributed Energy Resources

http://www.eere.energy.gov/der/basics.html

Making Connections: Case Studies of Interconnection Barriers and their Impact on

Distributed Power Projects (NREL)

http://www.nrel.gov/docs/fy00osti/28053.pdf

Office of Distributed Energy Resources

http://www.eere.energy.gov/der/about.html

Office of Electric Transmission and Distribution - Electric Distribution Transformation

Program

http://www.electricity.doe.gov/edt.htm

Technical Assessment of Current Interconnection Experience

http://www.eere.energy.gov/distributedpower/research/tacie.html

\section{EPRI}

Paths to Plug and Play Distributed Energy Resources: Plausible Scenarios of Increased Ease of Deployment in the Market (TR1004997)

http://www.epri.com/OrderableitemDesc.asp?product id $=000000000001004997$

\section{General Electric Corporate Research and Development}

Fact sheet: Integrating Distributed Generation with Electric Power

http://www.nrel.gov/docs/fy03osti/33402.pdf

\section{Institute of Electrical and Electronics Engineers}

Fact Sheet: Interconnection Standards Development

http://www.nrel.gov/docs/fy03osti/33405.pdf

\section{National Association of Regulatory Utility Commissioners}

Distributed Generation Expedited/Fast Track Interconnection Agreements Comparison:

National Association of Regulatory Utility Commissioners vs. FERC

http://www.westgov.org/wieb/meetings/crepcfall2002/briefing materials/naruc-

ferc_compare.pdf

\section{National Renewable Energy Laboratory}

Interconnection Publications

http://www.nrel.gov/publications/neon/archives/2003/021803.html

Massachusetts Technology Collaborative

Interconnection Standards Information

http://www.mtpc.org/RenewableEnergy/public policy/dg_interconnection_links.htm

\section{Public Renewables Partnership}

Connecting PV to the Grid

http://www.repartners.org/solar/pvgrid.htm 


\section{Underwriters Laboratories}

Listed DG Categories

http://www.ul.com/dge/categories.html

Fact sheet: Streamlined Interconnection

http://www.nrel.gov/docs/fy03osti/33398.pdf 


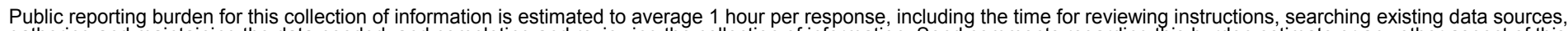

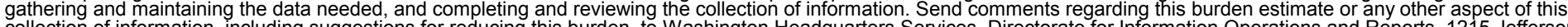
Davis Highway, Suite 1204, Arlington, VA 22202-4302, and to the Office of Management and Budget, Paperwork Reduction Project (0704-0188), Washington, DC 20503.
1. AGENCY USE ONLY (Leave blank)
2. REPORT DATE
November 2003
3. REPORT TYPE AND DATES COVERED Subcontract Report

4. TITLE AND SUBTITLE

DER Certification Laboratory Pilot, Accreditation Plan, and Interconnection Agreement Handbook

5. FUNDING NUMBERS

DP03.1001

NAD-1-30605-13

6. $\operatorname{AUTHOR}(\mathrm{S})$

T. Key, H.E. Sitzlar, and R. Ferraro

7. PERFORMING ORGANIZATION NAME(S) AND ADDRESS(ES)

EPRI PEAC Corp.

8. PERFORMING ORGANIZATION REPORT NUMBER

942 Corridor Blvd.

Knoxville, TN 37932

(865) 218-8082

9. SPONSORING/MONITORING AGENCY NAME(S) AND ADDRESS(ES)

National Renewable Energy Laboratory

1617 Cole Blvd.

Golden, CO 80401-3393

10. SPONSORING/MONITORING AGENCY REPORT NUMBER

NREL/SR-560-34588

11. SUPPLEMENTARY NOTES

NREL Technical Monitor: T. Basso

12a. DISTRIBUTION/AVAILABILITY STATEMENT

National Technical Information Service

12b. DISTRIBUTION CODE

U.S. Department of Commerce

5285 Port Royal Road

Springfield, VA 22161

13. ABSTRACT (Maximum 200 words)

This report describes the first steps toward creating the organization, procedures, plans and tools for distributed energy resources (DER) equipment certification, test laboratory accreditation, and interconnection agreements. It covers the activities and accomplishments during the first period of a multiyear effort. It summarizes steps taken to outline a certification plan to assist in the future development of an interim plan for certification and accreditation activities. It also summarizes work toward a draft plan for certification, a beta Web site to support communications and materials, and preliminary draft certification criteria.

14. SUBJECT TERMS

certification; accreditation; interconnection; standards; distributed energy resources; DER; distributed power; distributed generation; EPRI PEAC; Distribution and Interconnection R\&D; National Renewable Energy Laboratory; NREL

17. SECURITY CLASSIFICATION OF REPORT

Unclassified
18. SECURITY CLASSIFICATION OF THIS PAGE Unclassified
19. SECURITY CLASSIFICATION OF ABSTRACT Unclassified
15. NUMBER OF PAGES

16. PRICE CODE

20. LIMITATION OF ABSTRACT

UL 